\title{
Lack of Cyp1b1 promotes the proliferative and migratory phenotype of perivascular supporting cells
}

\author{
Tammy L Palenski ${ }^{1}$, Christine M Sorenson ${ }^{2}$, Colin R Jefcoate ${ }^{3}$ and Nader Sheibani ${ }^{1,4}$
}

Perivascular supporting cells, including pericytes and smooth muscle cells (PC/SMC), have an integral role during angiogenesis and control vascular remodeling, maturation, and stabilization of neoteric vessels. We recently showed that a Cyp1B1 deficiency in mice results in the attenuation of angiogenesis in vivo and the pro-angiogenic activity of endothelial cells in vitro. However, the contribution of PC/SMC, and more specifically the cell autonomous effects of Cyp1B1 in these processes, needs further investigation. Here we demonstrate that PC constitutively expressed Cyp1B1, and that a deficiency in Cyp1B1 was associated with enhanced proliferation, and decreased apoptosis. Mechanistically, the lack of Cyp1B1 was associated with increased oxidative stress and sustained NF- $\kappa$ B activation, which was reversed by the antioxidant $\mathrm{N}$-acetylcysteine. These changes were also concomitant with alterations in PC migration, adhesion, and expression of various extracellular matrix proteins, including thrombospondin-2. Cyp1B1-deficient PC also expressed decreased levels of vascular endothelial growth factor. Together, our results suggest an important role for Cyp1B1 expression in the regulation of PC proliferation, migration, and survival through modulation of the intracellular oxidative state and NF- $\kappa$ B expression and/or activity. Thus, a lack of Cyp1B1 in PC may have a significant role in vascular dysfunction and integrity, contributing to the attenuation of angiogenesis.

Laboratory Investigation (2013) 93, 646-662; doi:10.1038/labinvest.2013.55; published online 8 April 2013

KEYWORDS: angiogenesis; cell migration; extracellular matrix proteins; integrins; NF-KappaB; oxidative stress; signal transduction

Angiogenesis is a multistep process involving endothelial cell (EC) migration, proliferation and ultimately differentiation and formation of patent vessels. Endothelial cells stimulate the proliferation, migration, and recruitment of pericytes (PC) along the adjacent endothelial tubes by a steep gradient secretion of PDGF-BB from the tip cells. ${ }^{1-3}$ PC embed in the basement membrane shared with EC and extend long cytoplasmic processes along the EC tubes on their abluminal surface, at times spanning several EC. Studies over the last two decades have begun to reveal the pivotal role PC have in synthesis, remodeling and maintenance of the vascular basement membrane, local regulation of vascular tone, and promoting vascular stability. ${ }^{4}$ Vascular stability is attained through endothelial-PC interactions and concomitant deposition and remodeling of their extracellular matrix. Abnormal PC function is associated with many diseases including diabetic retinopathy, neonatal in- traventricular hemorrhage, cancer, and some neurodegenerative disorders. However, current knowledge is still lacking regarding many aspects of endothelial-PC heterotypic interactions and more specifically the role PC have in microvessel homeostasis and maintenance.

Cytochrome P450 enzymes utilize endogenous substrates, such as eicosapentaenoic acid, retinoic acid, linoleic acid, and arachidonic acid, to generate intracellular messengers, such as cis-epoxyeicosatrienoic acids, mid-chain cis-trans-conjugated dienols, or $\omega$-terminal alcohols, with important roles in the modulation of vascular tone, blood flow, and angiogenesis. ${ }^{5}$ The cytochrome P450 enzymes have been identified within the vascular wall, including Cyp1A1, Cyp1B1, Cyp2J2, and Cyp2B6. ${ }^{6}$ Cytochrome P450 1B1 (Cyp1B1) is an unusual member of the cytochrome P450 family of proteins. Gene structure reveals only two introns with a highly extended $3.5-\mathrm{kb} 3^{\prime}$-UTR, and a promoter that is rich in GC islands.

\footnotetext{
${ }^{1}$ Department of Ophthalmology and Visual Sciences, University of Wisconsin School of Medicine and Public Health, Madison, WI, USA; ${ }^{2}$ Department of Pediatrics, University of Wisconsin School of Medicine and Public Health, Madison, WI, USA; ${ }^{3}$ Department of Cell and Regenerative Biology, University of Wisconsin School of Medicine and Public Health, Madison, WI, USA and ${ }^{4}$ Department of Pharmacology, University of Wisconsin School of Medicine and Public Health, Madison, WI, USA Correspondence: Dr N Sheibani, PhD, Department of Ophthalmology and Visual sciences, University of Wisconsin, 600 Highland Avenue, K6/456 CSC, Madison, WI 53792-4673, USA
}

E-mail: nsheibanikar@wisc.edu

Received 15 November 2012; revised 12 February 2013; accepted 6 March 2013 
Nucleic acid and amino-acid sequence analysis revealed Cyp1B1 to have only 40\% homology with Cyp1A1.

Expression of Cyp1B1 is conserved in the early embryo across several species during the development of the neural crest, hindbrain and eyes. ${ }^{7-11}$ Cyp $1 \mathrm{~B} 1$ is constitutively expressed in extrahepatic epithelia, particularly mesenchymal cells and in stromal cells, including fibroblasts and vascular cells..$^{7,12-21}$ Cyp1B1 participates in the oxidative metabolism of xenobiotics, particularly the bioactivation of polycyclic aromatic hydrocarbons. Cyp1B1 metabolizes substrates of endogenous origin including retinol metabolism to retinal, the hydroxylation of melatonin, dietary plant flavanoids, and the formation of genotoxic catechol estrogens. ${ }^{21-23}$ Cyp1B1 has been implicated in autosomal recessive primary congenital glaucoma, ${ }^{24,25}$ conceivably as a result of maldevelopment of the eye anterior chamber angle. ${ }^{26}$ However, the molecular and cellular mechanisms by which Cyp1B1 expression influence the development and maintenance of ocular function remains unknown.

Recent studies conducted in our laboratory have established an important role for Cyp1B1 in the regulation of vascular EC and angiogenesis. ${ }^{14,27}$ In vivo, retinas from Cyp1b1-deficient (cyp1b1-/-) mice exhibited reduced vascular density and failed to undergo neovascularization during oxygen-induced ischemic retinopathy (OIR). We also observed decreased endothelial nitric oxide synthase (eNOS) staining in retinal blood vessels of cyp1b1-/- mice compared with cyp $1 b 1+/+$ mice, especially during OIR. We showed that Cyp1B1 is constitutively expressed in the retinal vasculature and vascular EC, and that a deficiency in Cyp1B1 in vitro resulted in decreased migration, attenuation of eNOS expression, and capillary morphogenesis of retinal EC. These defects were mainly attributed to increased intracellular oxidative stress, and were relieved by decreases in oxygen level $(2 \%)$ or addition of antioxidant, $\mathrm{N}$-acetylcysteine (NAC). ${ }^{14}$ We showed modulation of eNOS expression and NO synthesis, and/or its bioavailability is an important target of Cyp1B1-mediated EC function. ${ }^{27}$ In addition, microarray studies show dramatic upregulation of Cyp1B1 by arterial levels of shear stress in cultures of human EC. ${ }^{20}$ These results suggest an important role for Cyp1B1 in vascular development and homeostasis. However, expression of Cyp1B1 in perivascular supporting cells, including PC, and its deficiency on PC function remains to be explored.

Much investigation into the interactions between EC and PC has revealed that these two vascular cell types are interdependent, and that primary defects in one cell type may have obligatory consequences on the other. ${ }^{28,29}$ However, the expression and function of Cyp1B1 in PC that invest the microvessels requires further investigation. Using transgenic mice that carry an interferon- $\gamma$-inducible temperaturesensitive large T antigen, we isolated PC from cyp $1 b 1+/+$ and cyp $1 b 1-/-$ mice. Here we demonstrate that Cyp1B1 is constitutively expressed in PC, and its deficiency leads to increased oxidative stress, sustained NF- $\kappa \mathrm{B}$ p65 activation, and altered production of the matricellular proteins including increased expression of thrombospondin-2 (TSP2). These cells also exhibited alterations in the rate of proliferation and apoptosis, migration, adhesion to various extracellular matrix proteins, as well as their receptor expression, and decreased expression of vascular endothelial growth factor (VEGF). Together, our results suggest that the expression of Cyp1B1 in retinal PC is essential for maintaining the physiological function and integrity of the vasculature.

\section{MATERIALS AND METHODS Experimental Animals}

All experiments were carried out in accordance to the Association for Research in Vision and Ophthalmology Statement for the Use of Animals in Ophthalmic and Vision Research and were approved by the Institutional Animal Care and Use Committee of the University of Wisconsin School of Medicine and Public Health. Immortomice expressing a temperature-sensitive simian virus 40 large $\mathrm{T}$ antigen (Charles River Laboratories, Wilmington, MA) were backcrossed into C57BL/6j mice in our laboratory, and further crossed with cyp $1 b 1-/-$ mice, and generated in a C57BL/6j background. The immorto-cyp1b1-/ - mice were identified by PCR analysis of DNA isolated from tail biopsies. The PCR primer sequences were as follows: immorto forward: 5'-CCTCTGAGCTATTCCAGAAGTAGTG-3', immorto reverse: 5'-TTAGAGCTTTAAATCTCTGTAGGTAG-3'; Neomyacin forward: $5^{\prime}$-TTGGGTGGAGAGGCTATTCGGCTATGA-3', Neomycin reverse: 5'-GGCGCGAGCCCCTGATGCTC-3'; Cyp1B1 forward: 5'-CTGAGTTGGACCAGGTTGTGG-3'; Cyp1B1 reverse: $5^{\prime}$-CATGGATTCTAAACGACTAGG-3'.

\section{Tissue Preparation and Culture of Retinal PC}

PC were isolated from mouse retinas by collecting retinas from one litter (6-7 pups, 4 weeks old) using a dissecting microscope. Twelve to fourteen retinas were rinsed with serum-free Dulbecco's Modified Eagle Medium (DMEM; Invitrogen, Carlsbad, CA), pooled in a $60-\mathrm{mm}$ dish, minced, and digested for $45 \mathrm{~min}$ with collagenase type II $(1 \mathrm{mg} / \mathrm{ml}$, Worthington, Lakewood, NJ) with $0.1 \%$ BSA in serum-free DMEM at $37^{\circ} \mathrm{C}$. Cells were rinsed in DMEM containing $10 \%$ fetal bovine serum (FBS) and centrifuged for $5 \mathrm{~min}$ at $400 \mathrm{~g}$. The digested tissue was resuspended in $4 \mathrm{ml}$ DMEM containing 10\% FBS, $2 \mathrm{mM}$ L-glutamine, $100 \mu \mathrm{g} / \mathrm{ml}$ streptomycin, $100 \mathrm{U} / \mathrm{ml}$ penicillin, and murine recombinant IFN- $\gamma$ (R\&D Systems, Minneapolis, MN) at $44 \mathrm{U} / \mathrm{ml}$, and evenly divided into 4 wells of a 24 -well tissue culture plate and maintained at $33{ }^{\circ} \mathrm{C}$ with $5 \% \mathrm{CO}_{2}$. Cells were progressively passed to larger plates, maintained and propagated in $60-\mathrm{mm}$ tissue culture dishes. These cells express a temperature-sensitive large $\mathrm{T}$ antigen whose expression is induced in the presence of INF- $\gamma$ allowing the cells to readily propagate when cultured at $33^{\circ} \mathrm{C}$. The culture of these cells at $37^{\circ} \mathrm{C}$ in the absence of INF- $\gamma$ for $48 \mathrm{~h}$ results in loss of large T antigen. 


\section{Flow Cytometry}

Flow cytometry was used to assess the expression of PC markers and integrins in cyp $1 b 1+/+$ and cyp $1 b 1-/-$ PC. Confluent cultured cyp1b1+/+ and cyp1b1-/- PC from $60-\mathrm{mm}$ culture plates were rinsed with phosphate-buffered saline (PBS) containing $0.04 \%$ EDTA and incubated with $1.5 \mathrm{ml}$ of cell dissociation solution (Tris-buffered saline [20 mM Tris- $\mathrm{HCl}$ and $150 \mathrm{mM} \mathrm{NaCl}$; $\mathrm{pH}$ 7.6] TBS containing $2 \mathrm{mM}$ EDTA and $0.05 \% \mathrm{BSA})$. Cells were rinsed from plates with DMEM containing $10 \%$ FBS, washed once with $5 \mathrm{ml}$ of TBS and blocked in $0.5 \mathrm{ml}$ of TBS with $1 \%$ goat serum for $20 \mathrm{~min}$ on ice. Cells were centrifuged $5 \mathrm{~min}$ at $400 \mathrm{~g}$, medium aspirated, resuspended in $0.5 \mathrm{ml}$ TBS with $1 \%$ BSA containing an appropriate dilution of primary antibody (as recommended by the supplier), and incubated on ice for $30 \mathrm{~min}$. Cells were incubated with rabbit anti-NG2 (Millipore AB5320; Temecula, CA), rabbit anti-mouse $\alpha$-smooth muscle actin (Sigma; St Louis, MO), rat anti-mouse PECAM-1, antimouse CD36, rat-anti-mouse CD45, rat-anti-mouse Sca1, rat anti-mouse vascular cell adhesion molecule-1 (VCAM-1) (BD Pharmingen, San Diego, CA), rat anti-mouse PDGFR- $\beta$, rat anti-mouse CD11b (eBioscience, San Diego, CA), rat antimouse CD47 (a gift of Dr. William A. Frazier, Washington University, St. Louis, MO), rat anti-mouse VEGF-R1, and rat anti-mouse VEGF-R2 (R\&D Systems). For integrin expression analysis, rabbit anti- $\beta 1$-integrin (Santa Cruz Biotechnology, Santa Cruz, CA), rabbit anti- $\beta 8$-integrin, rabbit anti- $\alpha 2$-integrin, rabbit anti- $\alpha 3$-integrin, rabbit anti- $\alpha 4$-integrin, rat anti- $\alpha 5$-integrin, rabbit anti- $\alpha$-integrin, rabbit anti- $\alpha \mathrm{v}$-integrin, mouse anti- $\alpha 5 \beta 1$-integrin and mouse anti$\alpha \mathrm{v} \beta 3$-integrin (Millipore) for $30 \mathrm{~min}$ on ice. Cells were washed twice with TBS with $1 \%$ BSA and incubated with the appropriate FITC-conjugated secondary antibody for $30 \mathrm{~min}$ on ice. Cells were then washed twice with TBS with $1 \%$ BSA, resuspended in $0.5 \mathrm{ml}$ TBS with $1 \% \mathrm{BSA}$, and analyzed using the FACScan Caliber flow cytometer (Becton-Dickinson, San Jose, CA). The isotype control was FITC-labeled isotype IgG as specifically stated above. Ten thousand cells were analyzed for each sample and three independent experiments were performed with two different isolations of PC.

\section{Cell Proliferation}

Cell proliferation was performed by plating cyp $1 b 1+/+$ and cyp $1 b 1-/-$ retinal PC at $1 \times 10^{4}$ in triplicate per time point in $60-\mathrm{mm}$ tissue culture dishes. Cell numbers were counted every other day in triplicate for 7 days and fed on days they were not counted. The rate of DNA synthesis was measured using Click-iT EdU Alexa Fluor 488 kit as recommended by the supplier (Invitrogen). The assay measures incorporation of 5-ethynyl-2'-deoxyuridine (EdU), a nucleoside analogue of thymidine, during cell proliferation. Cyp $1 b 1+/+$ and cyp1b1-/ - retinal PC were plated at $5 \times 10^{5}$ cells on $60-\mathrm{mm}$ tissue culture dishes and were incubated with $10 \mu \mathrm{M}$ $\mathrm{EdU}$ in PC medium for $2 \mathrm{~h}$ at $33^{\circ} \mathrm{C}$. DNA synthesis was analyzed by measuring incorporated EdU using the FACSs- can Caliber flow cytometer (Becton-Dickinson). Ten thousand cells were analyzed for each sample and three independent experiments were performed with two different isolation of PC.

\section{Real-Time PCR Analysis}

Cyp1b1+/+ and cyp1b1-/- PC were allowed to reach $90 \%$ confluence, rinsed twice with PBS, scraped from $60-\mathrm{mm}$ tissue culture plates and transferred to Eppendorf tubes. Cells were centrifuged, immediately frozen in liquid nitrogen and stored at $-80^{\circ} \mathrm{C}$ until analysis. Total RNA was extracted by mirVana PARIS kit (Ambion) according to the manufacturer's instructions. The cDNA synthesis was performed using $1 \mu \mathrm{g}$ of total RNA and Sprint RT Complete-Double PrePrimed kit from (Clontech, Mountain View, CA). A volume of $1 \mu \mathrm{l}$ of each cDNA (dilution 1:10) was used as template in qPCR assays, performed in triplicate of three biological replicates on Mastercycler Realplex (Eppendorf, Hauppauge, NY) using the SYBR qPCR Premix (Clontech). Amplification parameters were as follows: $95^{\circ} \mathrm{C}$ for $2 \mathrm{~min} ; 40$ cycles of amplification $\left(95^{\circ} \mathrm{C}\right.$ for $15 \mathrm{~s}, 60^{\circ} \mathrm{C}$ for $\left.40 \mathrm{~s}\right)$; dissociation curve step $\left(95^{\circ} \mathrm{C}\right.$ for $15 \mathrm{~s}, 60^{\circ} \mathrm{C}$ for $15 \mathrm{~s}, 95^{\circ} \mathrm{C}$ for $15 \mathrm{~s})$. Standard curves were generated from known quantities for each target gene of linearized plasmid DNA. Ten times dilution series were used for each known target, which were amplified using SYBR-Green qPCR. The linear regression line for ng of DNA was determined from relative fluorescent units (RFU) at a threshold fluorescence value $(\mathrm{Ct})$ to quantify gene targets from cell extracts by comparing the RFU at the Ct to the standard curve, normalized by the simultaneous amplification of Rpl13A, which was used as a housekeeping gene to normalize all samples. The PCR primer sequences were: Bax forward: $5^{\prime}$-CCAAGAAGCTGAGCGAGTGTCT-3', reverse: 5'-AGCTCCATATTGCTGTCCAGTTC-3'; Bim-EL forward: 5'-AGTGTGACAGAGAAGGTGGACAATT-3', reverse: $5^{\prime}$-GGG ATTACCTTGCGGTTCTGT-3'; Bcl-2 forward: 5'-GGAGA GCGTCAACAGGGAGA-3', reverse: 5'-CAGCCAGGAGAAA TCAAACAGAG; TNF- $\alpha$ forward: $5^{\prime}$-ACCGTCAGCCGATTTG CTAT- ${ }^{\prime}$, reverse: $5^{\prime}$-TTGACGGCAGAGAGG AGGTT-3'; MCP-1 forward: $5^{\prime}$-GTCTGTGCTGACCCCAAGAAG- $3^{\prime}$, and

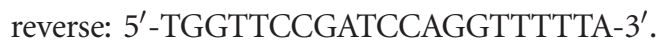

\section{Apoptosis and Cell Viability}

Apoptosis was determined by measuring caspase activation using Caspase-Glo 3/7-assay kit as recommended by the supplier (Promega, Madison, WI). The assay provides caspase-3/7 DEVD-aminoluciferin substrate and the caspase-3/7 activity is detected by luminescent signal. For the assay, cyp $1 b 1+/+$ and cyp $1 b 1-/-$ PC were plated at $8 \times 10^{3}$ per well of a 96-well plate. As an oxidative or apoptotic stimulus, PC were incubated with $150 \mu \mathrm{M}$ hydrogen peroxide $\left(\mathrm{H}_{2} \mathrm{O}_{2}\right.$; Fisher Scientific, Fair Lawn, NJ) or $10 \mathrm{nM}$ staurosporine (Invitrogen), in PC medium for $24 \mathrm{~h}$ at $33^{\circ} \mathrm{C}$. Caspase activity was detected using a luminescent microplate reader (Victa2 1420 Multilabel Counter, PerkinElmer; Waltham, 
MA). All samples were prepared in triplicate and repeated at least three times with similar results. Cellular viability of PC was determined using the CellTiter 96 Aqueous NonRadioactive cell proliferation assay (MTS; 3-(4,5-dimethylthiazol-2-yl)-5-(3-carboxymethoxyphenyl)-2-(4-sulfophenyl)-2H-tetrazolium; Promega). Cyp1b1 $+/+$ and cyp1b1 - / - PC were plated at $4 \times 10^{3}$ per well of a 96-well plate and incubated with $250 \mu \mathrm{M} \mathrm{H}_{2} \mathrm{O}_{2}$ for $48 \mathrm{~h}$ at $33^{\circ} \mathrm{C}$, and incubated further with MTS solution for $3 \mathrm{~h}$. The viability was determined by measuring absorbance at $490 \mathrm{~nm}$ using a microplate reader (Thermomax, Molecular Devices, Sunnyvale, CA), and determined as a percentage of control untreated cells. All samples were prepared in triplicate and repeated at least three times with similar results.

\section{Determination of the Level of Reactive Oxygen Species (ROS)}

The levels of oxidative stress were determined by staining cells with dihydroethidium (DHE; Invitrogen). DHE is oxidized to red fluorescent ethidium by $\mathrm{O}_{2}$-in the cytosol and interchalates in the DNA. Cells were plated at $5 \times 10^{4}$ cells in chamber slides (Lab-TEK; NUNC, Rochester, NY) coated with $2 \mu \mathrm{g} / \mathrm{ml}$ fibronectin (BD Biosciences, San Jose, CA) and incubated with $5 \mu \mathrm{M}$ TMS (Cayman Chemical), $200 \mu \mathrm{M}$ $\mathrm{H}_{2} \mathrm{O}_{2}, 1 \mathrm{mM}$ NAC or dimethyl sulfoxide (DMSO) for $24 \mathrm{~h}$. Cells were loaded with $10 \mu \mathrm{M}$ DHE for $20 \mathrm{~min}$ at $33^{\circ} \mathrm{C}$, washed with PC medium and returned to PC medium twice for two 30-min recovery periods. Fluorescent intensity was analyzed with a fluorescent microscope (Carl Zeiss Optical, Germany), and images were captured in digital format. Three independent experiments were performed. For quantitative assessment, the mean fluorescent intensities were determined using Image J 1.46a and representative images are shown.

\section{Indirect Immunofluorescence}

Cells were plated at $1 \times 10^{5}$ in chamber slides (Lab-TEK, NUNC) coated with $2 \mu \mathrm{g} / \mathrm{ml}$ fibronectin (BD Biosciences), washed in PBS, fixed with methanol for $15 \mathrm{~min}$ on ice, and blocked with $1 \%$ ovalbumin in TBS at $37^{\circ} \mathrm{C}$ for $20 \mathrm{~min}$. Slides were washed with TBS and incubated with anti-NG2 (1:200 dilution, Millipore) and anti- $\alpha$ SMA-FITC-conjugated (1:200 dilution, Sigma) in TBS containing $1 \%$ ovalbumin at $37^{\circ} \mathrm{C}$ for $40 \mathrm{~min}$. After washing with TBS, cells were incubated with appropriate Cy3-conjugated secondary antibody (1:500 dilution in TBS containing $1 \%$ ovalbumin) at $37^{\circ} \mathrm{C}$ for $40 \mathrm{~min}$. Cells were washed with TBS three times, mounted with a 1:1 TBS:glycerol solution with DAPI, and analyzed with a fluorescent microscope (Carl Zeiss Optical, Germany). Images were captured in digital format. Three independent experiments were performed and representative images are shown.

\section{Scratch Wound Assay}

Cells were plated at $8 \times 10^{5}$ cells in 60 -mm tissue culture dishes and allowed to reach confluence. Cell monolayers were wounded with a 1-ml micropipette tip, rinsed with DMEM containing 10\% FBS twice and fed with PC medium containing $1 \mu \mathrm{M} 5$-fluorouracil (Sigma) to exclude the potential contribution of cell proliferation to wound closure. The wound closure was monitored and photographed at $0,24,48$ and $72 \mathrm{~h}$ using a phase microscope in digital format. For quantitative assessment, the distances migrated as percent of total distance were determined. All samples were repeated at least three times with two different isolations of PC with similar results.

\section{Transwell Migration}

Transwell filters (Corning, Acton, MA) were coated with $2 \mu \mathrm{g} / \mathrm{ml}$ fibronectin in PBS and incubated overnight at $4{ }^{\circ} \mathrm{C}$. The bottom of the transwell was rinsed with PBS and blocked with $2 \%$ BSA in PBS for $1 \mathrm{~h}$ at room temperature. The transwell was rinsed with PBS, and $500 \mu \mathrm{l}$ serum-free DMEM was added to the bottom of each well and $1 \times 10^{5}$ cells in $100 \mu \mathrm{l}$ of serum-free medium were added to the top of the transwell membrane. Following $4 \mathrm{~h}$ in a $33^{\circ} \mathrm{C}$ tissue culture incubator, the cells and medium were aspirated and the upper side of the membrane wiped with a cotton swab. The cells that had migrated through the membrane were fixed with $4 \%$ paraformaldehyde, stained with hematoxylineosin, and mounted on a slide. Ten high-power fields $(\times 200)$ of cells were counted for each condition and the average and s.e.m. were determined. All samples were prepared in duplicate and the experiment repeated at least three times with similar results.

\section{Cell Adhesion}

Cell adhesion to various extracellular matrix proteins was performed as previously described. ${ }^{30}$ Varying concentrations of fibronectin, human type I collagen, vitronectin, and laminin (BD Biosciences) prepared in TBS with $\mathrm{Ca}^{2+} \mathrm{Mg}^{2+}$ ( $2 \mathrm{mM}$ each; TBS with $\mathrm{Ca}^{2+} \mathrm{Mg}^{2+}$ ) were coated on 96-well plates $(50 \mu \mathrm{l}$ per well; Nunc Maxisorbe plates, Fisher Scientific) overnight at $4{ }^{\circ} \mathrm{C}$. Plates were then rinsed four times with TBS with $\mathrm{Ca}^{2+} \mathrm{Mg}^{2+}$ and blocked with $200 \mu$ l of $1 \%$ BSA prepared in TBS with $\mathrm{Ca}^{2+} \mathrm{Mg}^{2+}$ for at least $1 \mathrm{~h}$ at room temperature. Cells were removed using $1.5 \mathrm{ml}$ of dissociation solution, washed once with TBS and resuspended at $5 \times 10^{5}$ cells per $\mathrm{ml}$ in HEPES-buffered saline ( $25 \mathrm{mM}$ HEPES, $\mathrm{pH} 7.60$, and $150 \mathrm{mM} \mathrm{NaCl}, 4 \mathrm{mg} / \mathrm{ml}$ BSA). After blocking, plates were rinsed with TBS $\mathrm{Ca}^{2+} \mathrm{Mg}^{2+}$ once, $50 \mu \mathrm{l}$ of cell suspension was added to each well containing $50 \mu$ l of TBS with $\mathrm{Ca}^{2+} \mathrm{Mg}^{2+}$, and the cells were allowed to adhere for $90 \mathrm{~min}$ at $37^{\circ} \mathrm{C}$ in a humidified incubator. Non-adherent cells were removed by gently washing the plate four times with $200 \mu$ l of TBS with $\mathrm{Ca}^{2+} \mathrm{Mg}^{2+}$ until no cells were left in wells coated with BSA. The number of adherent cells in each well was quantified by measuring the levels of intracellular acid phosphatase by lysing adherent cells in $100 \mu \mathrm{l}$ of lysis buffer $(50 \mathrm{mM}$ sodium acetate $\mathrm{pH} 5.0,1 \%$ Triton X-100, $4 \mathrm{mg} / \mathrm{ml}$ p-nitrophenyl 
phosphate) and incubating at $4{ }^{\circ} \mathrm{C}$ overnight. The reaction was neutralized by adding $50 \mu \mathrm{l}$ of $1 \mathrm{M} \mathrm{NaOH}$ and the absorbance was determined at $405 \mathrm{~nm}$ using a microplate reader (Thermomax, Molecular Devices). All samples were prepared in triplicate and experiments repeated at least three times with similar results.

\section{Western Blot Analysis}

Cells were plated at $5 \times 10^{5}$ in 60 -mm culture dishes and allowed to reach $\sim 90 \%$ confluence in 2 days. Cells were then rinsed once with serum-free DMEM and incubated with serum-free growth medium for 2 days. Conditioned medium was collected and clarified by centrifugation. Cells were rinsed once in $0.04 \%$ EDTA in PBS and lysed in $100 \mu \mathrm{l}$ of lysis buffer (50 mM HEPES pH 7.5, $100 \mathrm{mM} \mathrm{NaCl}, 0.1 \mathrm{M}$ EDTA, $1 \mathrm{mM} \mathrm{CaCl}, 1 \mathrm{mM} \mathrm{MgCl}, 1 \%$ Triton X-100, $1 \%$ NP-40, $0.5 \%$ deoxycholate, and protease inhibitor cocktail (Roche Biochemicals, Mannheim, Germany)), briefly sonicated and centrifuged at $14000 \mathrm{~g}$ for $10 \mathrm{~min}$ at $4{ }^{\circ} \mathrm{C}$. In some cases, total protein lysates were prepared from these samples in a modified lysis buffer ( $2 \mathrm{mM}$ orthovandate, $2 \mathrm{mM}$ sodium fluoride). Protein concentrations were determined using the bicinchoninic acid method (Pierce, Rockford, IL). Samples were adjusted for protein content $(50 \mu \mathrm{g})$, mixed with appropriate volume of $6 \times$ SDS-sample buffer, and analyzed by SDS-PAGE ( $4-20 \%$ Tris-glycine gels, Invitrogen). Proteins were transferred to nitrocellulose membrane and incubated in blocking buffer $(0.05 \%$ Tween-20 and 5\% skim milk in TBS) for $1 \mathrm{~h}$ at room temperature. Membranes were then incubated with mouse anti-human TSP1 (A6.1 Neo Markers, Fremont, CA), mouse anti-TSP2 (BD Pharmingen), rabbit anti-rat fibronectin, anti- $\beta$-actin (Sigma), rat anti-chicken tenascin-C (Milipore, AB19013), goat anti-mouse osteopontin, anti-VEGF-R1, anti-JNK, anti-phospho-JNK (R\&D Systems), rabbit anti-Akt, rabbit anti-phospho-Akt, rabbit anti-Erk1/2, mouse anti-phospho-Erk1/2, rabbit anti-p38, rabbit anti-phospho-p38 (Cell Signaling), rabbit anti-p65, rabbit anti-phospho-p65, rabbit anti-STAT3, and mouse antiphospho-STAT3 (Santa Cruz). Membranes were washed, incubated with horseradish-peroxidase-conjugated secondary antibody (1:5000, Jackson ImmunoResearch Laboratories, West Grove, PA) for $1 \mathrm{~h}$ at room temperature, and the protein was visualized according to the chemiluminescent procedure (Chemiluminescence reagent; GE Biosciences). The mean band intensities were measured densitometrically using Image J 1.46a.

\section{Capillary Morphogenesis}

Tissue culture plates $(35 \mathrm{~mm})$ were coated with $0.5 \mathrm{ml} \mathrm{Ma}$ trigel $(10 \mathrm{mg} / \mathrm{ml}$; BD Bioscience) and allowed to harden at $37^{\circ} \mathrm{C}$ for at least $30 \mathrm{~min}$. Cells were removed using trypsin/ EDTA, washed with DMEM containing 10\% FBS, centrifuged at $400 \mathrm{~g}$ for $5 \mathrm{~min}$, and suspended at $2 \times 10^{5} \mathrm{cells} / \mathrm{ml}$ in EC growth medium without serum. Retinal EC and PC were used at a 1:1 ratio. Cells in a 2-ml volume were applied to the
Matrigel-coated plates and photographed after $18 \mathrm{~h}$ using a Nikon microscope in a digital format. For quantitative assessment of the data, the mean number of branch points was determined by counting the number of branch points in five fields $(\times 20)$. These experiments were repeated with three different isolation of cells.

\section{VEGF Analysis}

VEGF protein levels produced by cyp $1 b 1+/+$ and cyp1b1-/ - PC were determined using a Mouse VEGF Immunoassay kit ( $R \& D$ Systems). Cells were plated at $6 \times 10^{5}$ cells on $60-\mathrm{mm}$ tissue culture dishes and allowed to reach $\sim 90 \%$ confluence. The cells were then rinsed once with serum-free DMEM and were grown in serum-free medium for 2 days. Conditioned medium was centrifuged at $400 \mathrm{~g}$ for $5 \mathrm{~min}$ to remove cell debris, and $50 \mu \mathrm{l}$ was used in the VEGF Immunoassay. The assay was performed in triplicate as recommended by the manufacturer and was normalized to the number of cells. The amount of VEGF was determined using a standard curve generated with known amounts of VEGF in the same experiment. These experiments were repeated three times with two different isolations of cells.

\section{Statistical Analysis}

Statistical differences between samples were evaluated when appropriate with student's unpaired $t$-test (two-tailed), twoway ANOVA with Bonferroni correction for multiple comparisons, or linear regression statistics to compare slopes for statistical significance. Data are represented as mean \pm s.e.m. Each result is representative of at least three independent experiments. All statistical assessments were evaluated at the 0.05 level of significance. Statistical analyses were performed with GraphPad Prism statistical software (GraphPad Software, La Jolla, CA).

\section{RESULTS \\ Cyp1B1 is Constitutively Expressed in Retinal PC}

To gain insight into the cell autonomous role Cyp1B1 has in PC function, retinal PC were isolated from cyp $1 b 1+/+$ and cyp1b1-/- Immortomice. Both cyp1b1+/+ and cyp1b1-/ - PC exhibited similar irregular, stellate morphology when plated on tissue culture plates (Figure 1a). We next assessed the expression of Cyp1B1 by western blot analysis of lysates prepared from $c y p 1 b 1+/+$ and cyp $1 b 1-/-$ retinal PC incubated with DMSO (control) or 2,3,7,8Tetrachlorodibenzodioxin (TCDD; $10 \mathrm{nM}$ ) for $24 \mathrm{~h}$. Figure 1b demonstrates constitutive expression Cyp1B1 in retinal PC, which was further induced in the presence of TCDD, a known inducer of Cyp1B1. ${ }^{19}$ Cyp1B1 was absent in the cyplb1-/ - retinal PC as expected. Purified human Cyp1B1 protein was used as a positive control. Cyp1B1 was also expressed in PC prepared from vascular beds of other mouse tissues, including heart and kidney (Figure 1c). Others have also reported expression of Cyp1B1 in both human and 
a

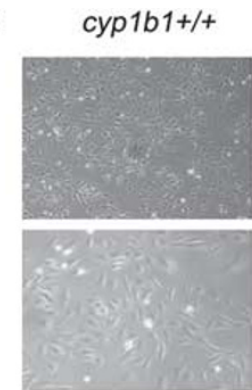

d
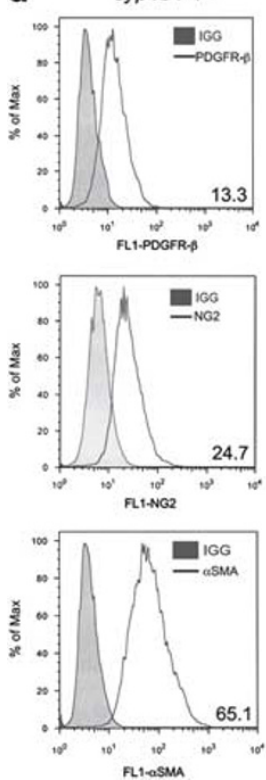

сур1b1-/-

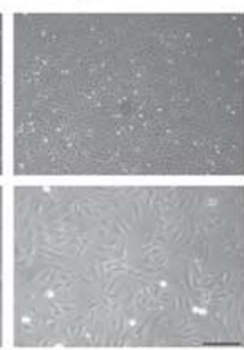

cyp1b1\%
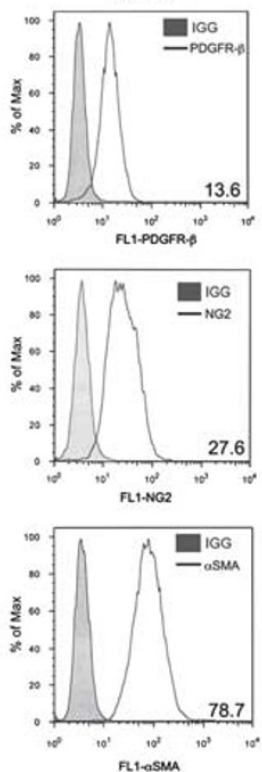

b
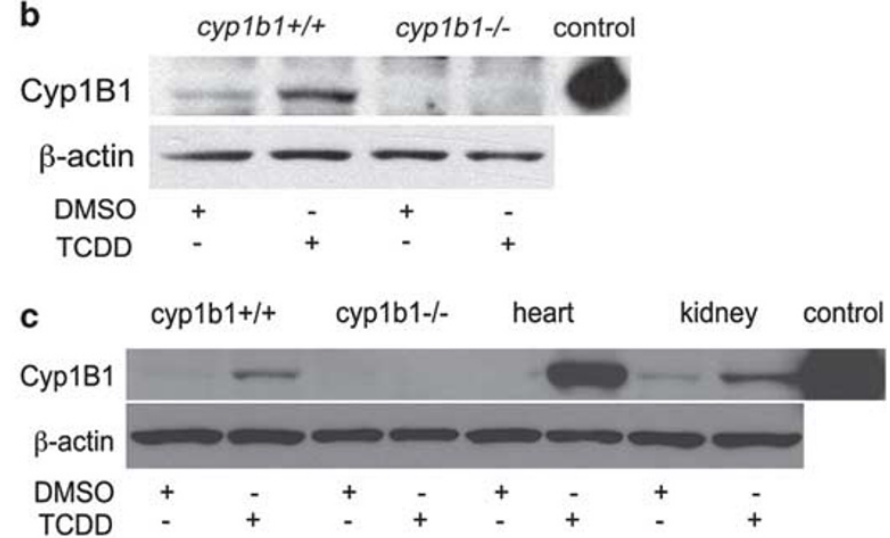

$e$
$+\frac{5}{5}$
$+\frac{0}{5}$
aSMANCy2

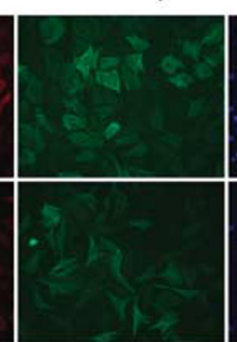

DAPI

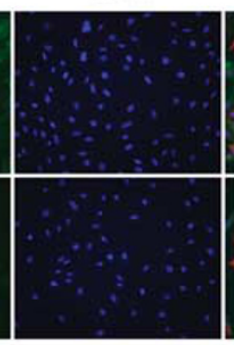

Merged

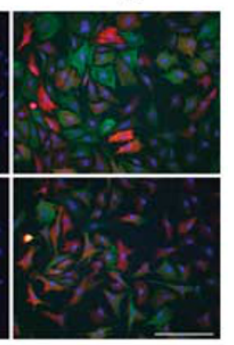

Figure 1 Isolation and characterization of mouse retinal pericytes (PC). (a) Cyp $1 b 1+/+$ and cyp $1 b 1-/-$ PC were photographed in digital format at $\times 40$ (top panels) and $\times 100$ (bottom panels) magnification. Scale bar in top panel indicates $100 \mu \mathrm{m}$; bottom panels, $20 \mu \mathrm{m}$. (b,c) Cyp1B1 expression in retina, heart, and kidney PC incubated with dimethyl sulfoxide (DMSO) or $10 \mathrm{nM}$ 2,3,7,8-Tetrachlorodibenzodioxin (TCDD) for $48 \mathrm{~h}$ was evaluated by western blot analysis of cell lysates $(50 \mu \mathrm{g})$. Purified recombinant human Cyp1B1 protein was used as a positive control. $\beta$-actin was used to assess loading. (d) Cyp $1 b 1+/+$ and cyp $1 b 1-/-$ PC were examined for expression of platelet-derived growth factor- $\beta$ (PDGFR- $\beta$ ), neuroglia proteoglycan 2 (NG2), and alpha-smooth muscle actin ( $\alpha$-SMA) by flow cytometry. Representative mean fluorescent intensities are indicated in bottom right corner of each panel. (e) Indirect immunofluorescent staining using NG2 and $\alpha$ SMA was performed to demonstrate culture purity. DAPI was used to stain cell nuclei. Scale bars, $50 \mu \mathrm{m}$.

murine aortic vascular SMC, as well as PC in human colon tissues. ${ }^{16,31,32}$ We next examined the PC marker expression to ensure these cells retained PC characteristics. Cyp $1 b 1+/+$ and cyp $1 b 1-/-$ PC were positive for platelet-derived growth factor-receptor $\beta \quad($ PDGF-R $\beta)$, neuroglia proteoglycan 2 (NG2), and alpha-smooth muscle actin ( $\alpha$ SMA) (Figure 1d). We also determined the purity of our retinal PC population via immunofluorescence staining using NG2, $\alpha$ SMA and DAPI (Figure 1e). Both cell types stained positive for NG2 and $\alpha$ SMA. Approximately $95 \%$ of the cells were positive for both NG2 and $\alpha$ SMA. Approximately $5 \%$ of the cells were only positive for NG2 or $\alpha$ SMA.

We analyzed the expression of other vascular cell markers in cyp $1 b 1+/+$ and cyp1b1-/ - retinal PC by flow cytometry (Figure 2). As expected, PC did not express the endothelial-specific marker PECAM-1 or VEGF-R2, but expressed significant amounts of VEGF-R1, CD36 and
VCAM-1. PC also expressed CD47, the thrombospondin-1 (TSP1) carboxyl terminal receptor, which is crucial for PC migration. ${ }^{33}$ We also examined the presence of markers reported to be expressed by hematopoietic and mesenchymal stem cells, respectively, which are known for their potential to produce vascular supporting cells, including CD11b and Sca1. ${ }^{34}$ We further assessed the levels of vascular endothelial growth factor-receptor 1 (VEGF-R1) by western blot analysis (Figure 2b). The quantitative assessment of the data revealed a $25 \%$ decrease in VEGF-R1 in the cyp1b1-/- PC compared with cyp $1 b 1+/+$ cells. Cyp $1 b 1-/-$ PC exhibited an $\sim 80 \%$ decrease in expression of VCAM-1 (Figure 2d) by flow cytometry.

\section{Cyp1b1 - /- PC Exhibited Enhanced Proliferation}

We next determined the impact of a cyp1B1 deficiency on the rate of proliferation and apoptosis of PC. The rates of pro- 
a
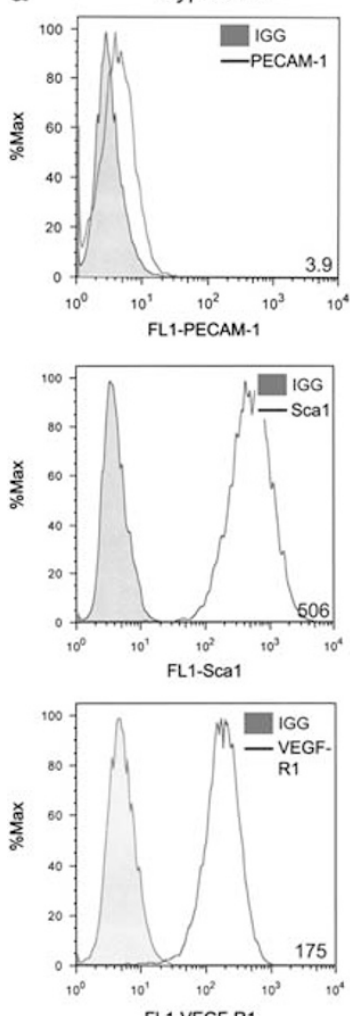

FL1-VEGF-R1

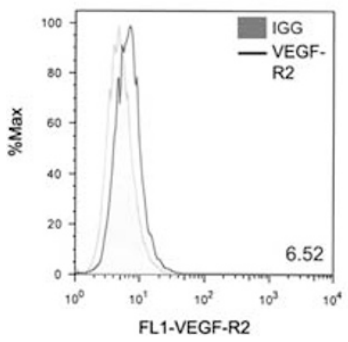

b

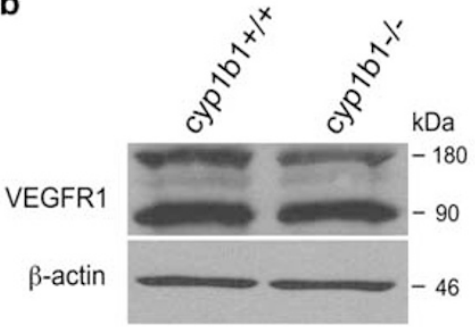

Cyp1b1-/
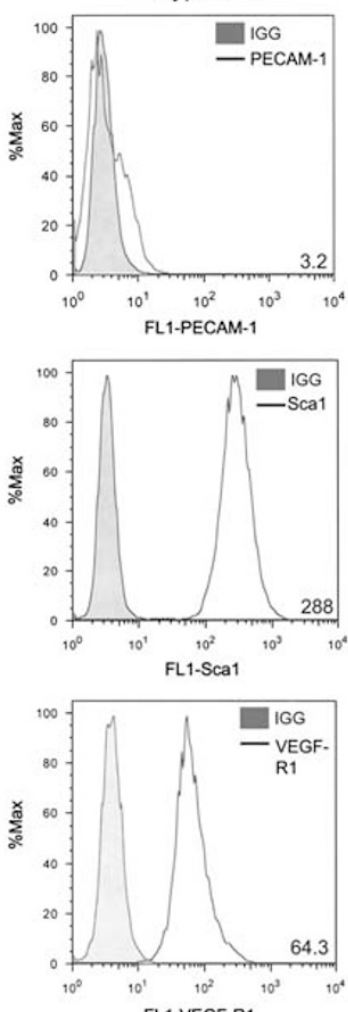

FL1-VEGF-R1

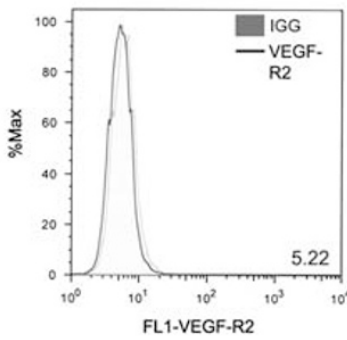

Cyp1b1+/+
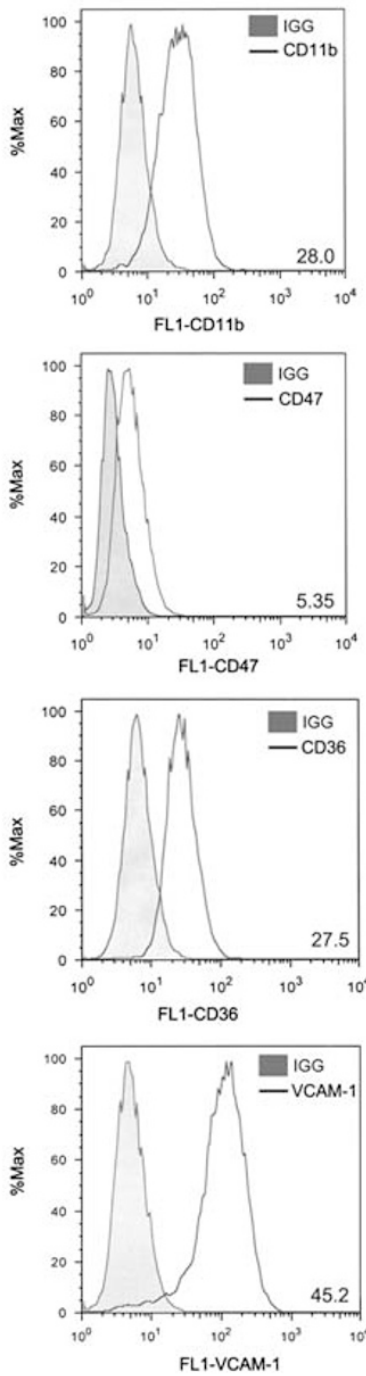

Cyp1b1-/-
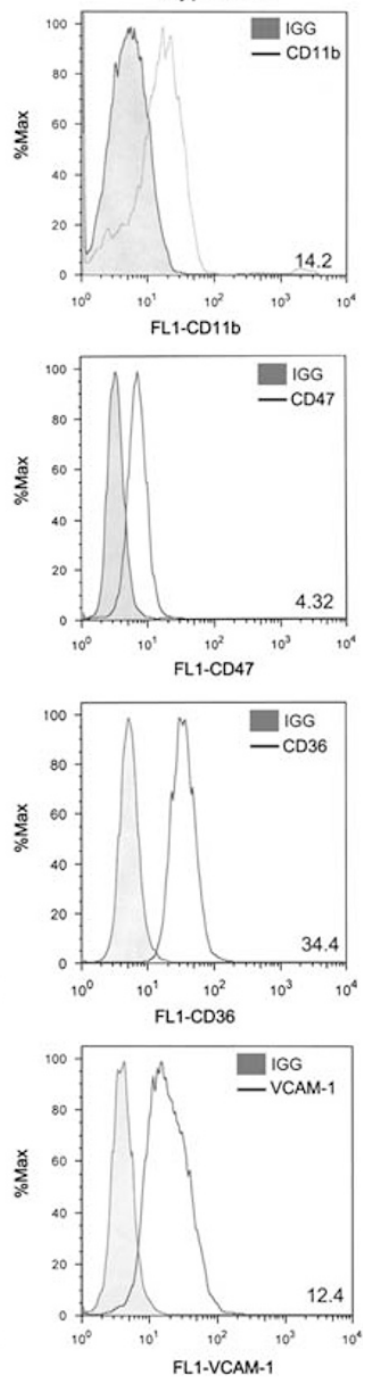

C

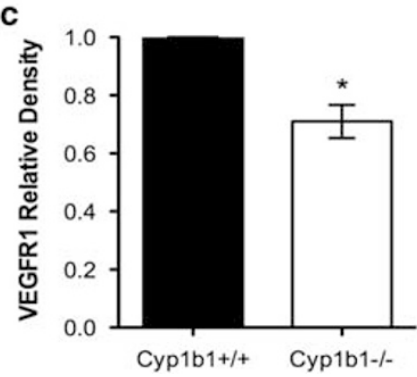

d

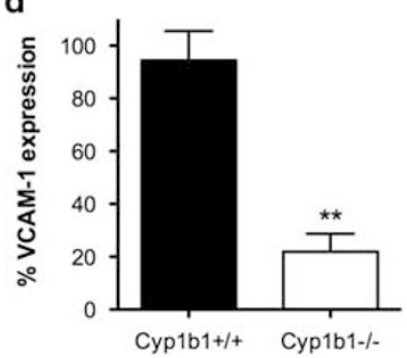

Figure 2 Retinal pericytes (PC) express other vascular cell markers. (a) Expression of PECAM-1, Sca1, VEGF-R1, VEGF-R2, CD11b, CD36, CD47, and VCAM1 were determined by flow cytometry. Representative mean fluorescent intensities are indicated in bottom right corner of each panel. Shaded areas show staining in the absence of primary antibody. (b) Expression of VEGF-R1 was analyzed by western blot. A representative image is shown. (c) Mean relative density for VEGF-R1 was determined $\left(n=2,{ }^{*} P<0.05\right)$. (d) Percent expression of VCAM-1 was determined by flow cytometry $\left(N=3,{ }^{* *} P<0.01\right)$.

liferation in cyp1b1+/+ and cyp1b1-/- PC were determined by counting the cell numbers. We observed a significant increase in proliferation of cyplb1-/- PC compared with cyp1b1+/+ cells (Figure 3a). To determine whether the increased proliferation was due to an increased rate of DNA synthesis, we calculated the percentage of cells undergoing active DNA synthesis using EdU labeling. The cyp1b1-/ - PC displayed comparable levels of DNA synthesis with cyp1b1+/+ PC (Figure 3b). We next addressed whether the increased proliferation was due to a decrease in the rate of apoptosis. Apoptotic cell death was determined by evaluation of the activation status of 

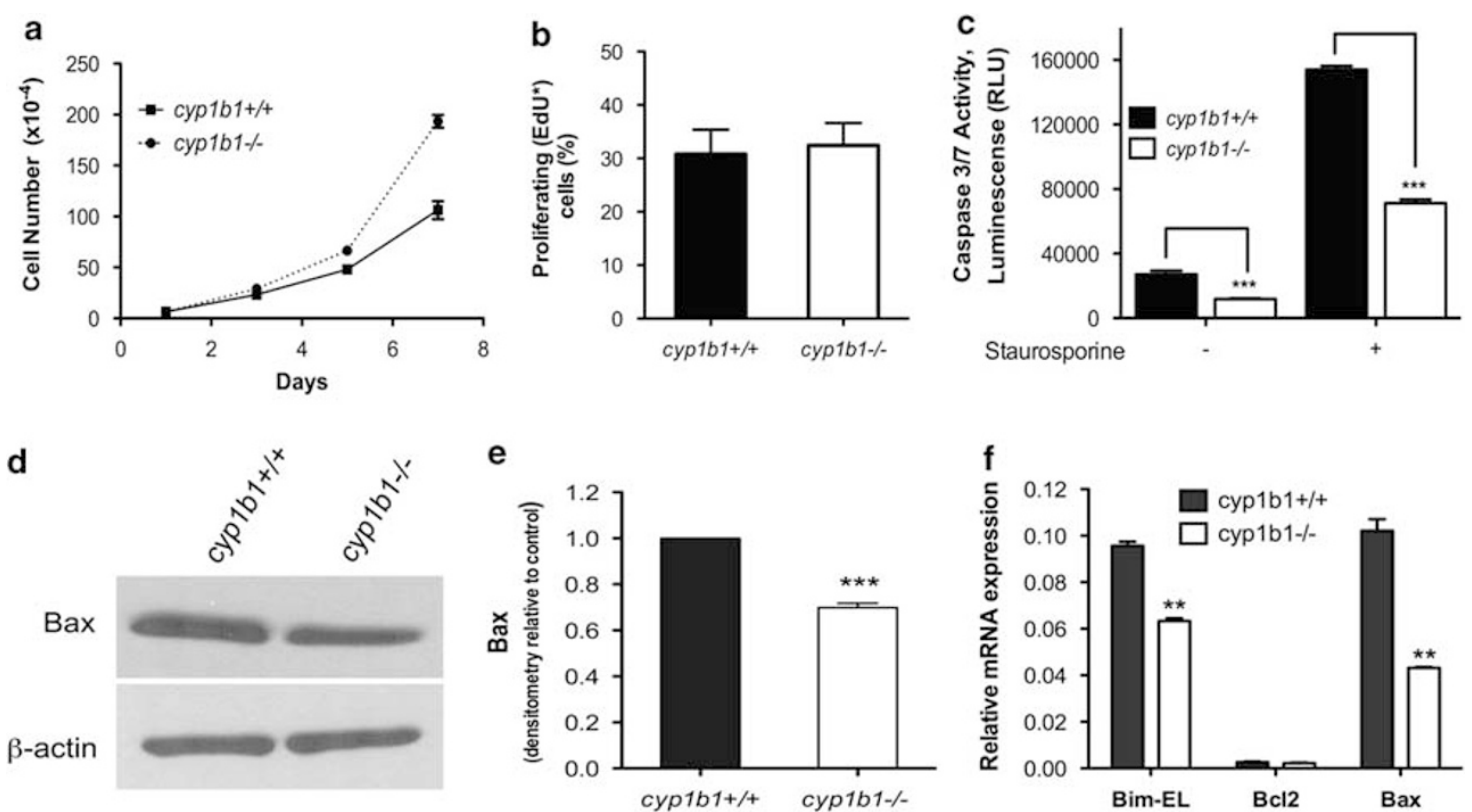

Figure 3 Lack of Cyp1B1 in retinal pericytes (PC) resulted in increased proliferation and decreased apoptosis. (a) The rate of cell proliferation was increased in cyp $1 b 1-/-P C$ compared with wild-type cells by counting the cell numbers. (b) Cyp1b1+/+ and cyp1b1-/- PC display similar rates of DNA synthesis by flow cytometry $(P>0.05)$. (c) The rate of apoptosis was determined by measuring caspase activity with luminescent signal from caspase-3/7 DEVD-aminoluciferin substrate. Cyp161 - / - PC demonstrated a twofold decrease in basal levels of caspase-3/7 and a twofold decrease when challenged with $10 \mathrm{nM}$ staurosporine. RLU, relative luminescence unit. (d) Expression of Bax was analyzed by western blotting. The $\beta$-actin level was assessed as a loading control. (e) Quantification of band intensity demonstrated a 1.4-fold decrease in Bax expression in the cyp1b1 - / - PC. $\left({ }^{* *} \mathrm{P}<0.001,{ }^{* * *} \mathrm{P}<0.0001\right)$. (f) Relative mRNA expression of Bim-EL, Bax, and Bcl-2 was analyzed by real-time $\mathrm{PCR}\left(N=3,{ }^{* *} P<0.001\right)$.

caspase-3/7 in cyp1b1+/+ and cyp1b1-/- PC. The cyp $1 b 1$ - / - PC displayed a twofold decrease in caspase-3/7 activation under basal conditions (Figure 3c). Staurosporine is a known inducer of apoptosis in many cell types. Upon challenge with $10 \mathrm{nM}$ staurosporine for $24 \mathrm{~h}$, cyp $1 b 1-/-$ PC exhibited a twofold decrease in staurosporine-induced apoptosis compared with wild-type cells (Figure 3c).

To gain further insight into the role Cyp1B1 has in apoptosis, we examined the expression of pro- and antiapoptotic members of the bcl-2 family. The bcl-2-associated$\mathrm{x}$ protein $(\mathrm{Bax})$ and Bim promote apoptosis by competing directly with bcl-2, an anti-apoptotic family member. Bax and Bim expression were lower in cyplb1 - / - PC compared with wild-type cells (Figure $3 \mathrm{~d}-\mathrm{f}$ ). However, no significant change was observed in bcl-2 expression levels. The gene expression results were confirmed by western blotting for Bax (Figure 3d and e). Unfortunately, high-quality antibodies for detection of mouse bcl-2 and Bim are not commercially available. Thus, cyp1b1-/- PC expressed lower levels of Bax and Bim, and exhibited lower rates of apoptosis.

Increased Cellular Oxidative Stress in cyp1b1-/- PC Many vascular pathologies and dysfunctions are presented with alterations in the cellular oxidative state. Oxidative and/ or reductive reactions catalyzed by Cyp1B1 may have a significant role in the modulation of the vascular reductive state. We addressed whether exposure of cyp1b1+/+ and cyp $1 b 1-/-$ PC to oxidative stress differentially impacted their viability. Cyp $1 b 1+/+$ and $c y p 1 b 1-/-$ PC were challenged with $150 \mu \mathrm{M} \mathrm{H}_{2} \mathrm{O}_{2}$ for $48 \mathrm{~h}$. Figure $4 \mathrm{a}$ shows that cyp $1 b 1-/-$ PC exhibited a twofold decrease in cell viability upon challenge with $\mathrm{H}_{2} \mathrm{O}_{2}$.

We next determined the level of ROS in cyp $1 b 1+/+$ and cyp1b1 - / - PC using DHE staining. In Figure 4b, cyp1b1 - /PC exhibited increased fluorescence compared with $c y p 1 b 1+1+$ PC, indicating higher levels of ROS in these cells. Furthermore, Cyplb1+/+ cells incubated with Cyp1B1 inhibitor, TMS, displayed increased fluorescence, similar to cyp1b1-/- PC. Incubation with antioxidant NAC in the cyp $1 b 1-/-$ PC revealed decreased fluorescence, indicating reduced levels of ROS. Both cell types exhibited increased fluorescence after exposure to $\mathrm{H}_{2} \mathrm{O}_{2}$; however, cyp $1 b 1-1-$ PC exhibited a twofold increase in ROS levels after $\mathrm{H}_{2} \mathrm{O}_{2}$ compared to wild-type cells exposed to $\mathrm{H}_{2} \mathrm{O}_{2}$ (Figure 4c). Thus, expression and/or activity of Cyp1B1 play a significant role in maintaining the $\mathrm{PC}$ reductive state.

\section{Cyp1b1 - / - PC are More Migratory and More Adhesive}

The ability of PC to migrate and embed into the vascular basement membrane of the endothelium is essential for the maturation and stabilization of newly forming vessels. ${ }^{35} \mathrm{We}$ next examined the migratory characteristics of cyp $1 b 1+/+$ and cyplb1-/- PC using a scratch wound assay. We observed accelerated wound closure in the cyp1b1-/- PC compared with cyp $1 b 1+/+$ PC after $72 \mathrm{~h}$ (Figure $5 \mathrm{a}$ and b). Similar results were observed using a transwell migration 


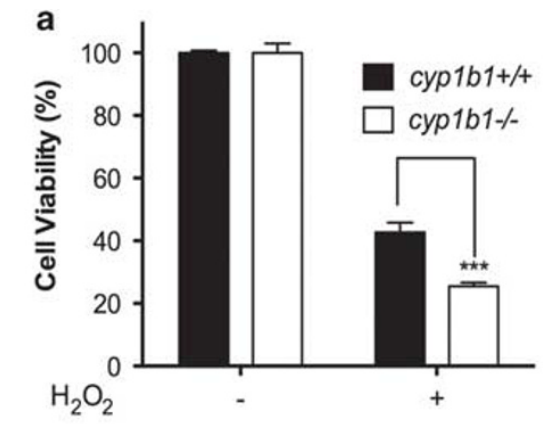

b
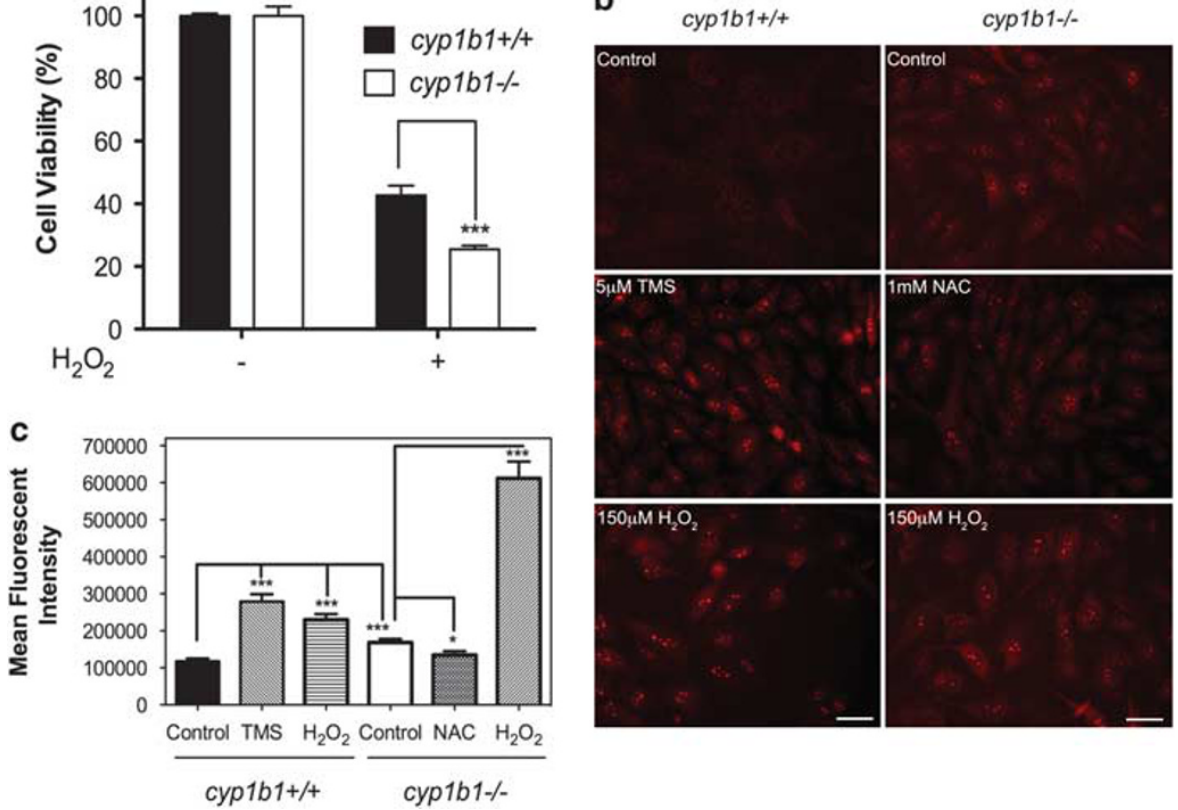

Figure 4 Cyp $161-/$ - retinal pericytes (PC) display higher oxidative stress. (a) Hydrogen peroxide $\left(\mathrm{H}_{2} \mathrm{O}_{2}\right)$ toxicity of retinal PC was measured using the MTS assay. Cyp $1 b 1+/+$ and cyp $1 b 1-/-\mathrm{PC}$ were incubated with $150 \mu \mathrm{M} \mathrm{H}_{2} \mathrm{O}_{2}$ for $48 \mathrm{~h}$ and demonstrated a 1.7-fold decrease in cell viability $\left({ }^{* *} P<0.0001\right)$. (b) Oxidative stress was measured by dihydroethidium staining in the presence of solvent control DMSO; Cyp1B1 inhibitor, TMS; antioxidant, NAC; and $\mathrm{H}_{2} \mathrm{O}_{2}$ for $48 \mathrm{~h}$. Scale bar, $20 \mu \mathrm{m}$. (c) Quantitative assessment of mean fluorescent intensity is shown $\left({ }^{*} P<0.05\right.$; $\left.{ }^{* * *} P<0.0001\right)$.
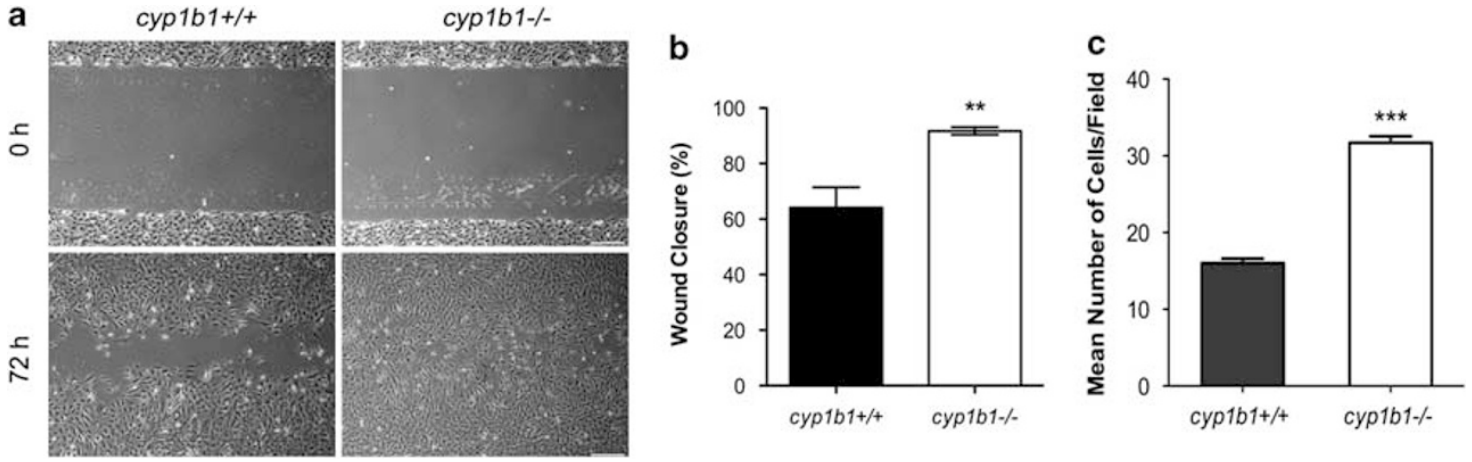

Figure 5 Cyp $1 b 1-/$ - retinal pericytes (PC) are more migratory. (a) Cell migration was determined by scratch wounding cell monolayers on uncoated tissue culture plates. Wound closure was monitored by photography. Scale bar indicates $100 \mu \mathrm{m}$. (b) Quantitative assessment of the data demonstrates an increase in wound closure in the cyp $1 b 1-/-P C(* * P<0.001)$. (c) Transwell migration assays were performed to confirm the migration results. Cyp $161-/$ - PC demonstrated a twofold increase in migration $(* * *<<0.0001)$.

assay. Cyp1b1-/ - PC demonstrated a twofold increase in the number of cells, which migrated through the membrane compared to cyp $1 b 1+/+$ cells (Figure $5 c$ ).

Alterations in the migratory properties of cyp $1 b 1-/-$ PC suggested that changes in their adhesive properties may occur. We next examined the cells' ability to adhere to various ECM proteins, including fibronectin, collagen I, laminin, and vitronectin (Figure 6). We observed a significant increase in the adhesion of cyp $1 b 1-/-$ PC to fibronectin, collagen I, and vitronectin compared with cyplb1 $1+/+$ PC. Minimal adhesion to laminin was observed for both cell types.
Cell adhesion and migration requires binding to the ECM proteins through specific cell surface integrins. To determine whether the alterations observed in adhesion and migration of cyp1b1-/ - PC were in part due to altered integrin expression, we analyzed the expression of various integrins on the surface of cyp1b1+/+ and cyp1b1-/- PC (Figure 7). Cyp1b1 $+/+$ and cyp1b1 - / - PC expressed similar levels of $\alpha 2, \alpha 3, \alpha 4, \alpha \mathrm{V}, \beta 1, \beta 8, \alpha 5 \beta 1$, and $\alpha \mathrm{V} \beta 3$. Representative mean fluorescent intensities are shown in Figure 7a. However, cyp1b1-/- PC expressed decreased levels of $\alpha 5$ and $\alpha 7$ integrins. The quantitative assessment of 

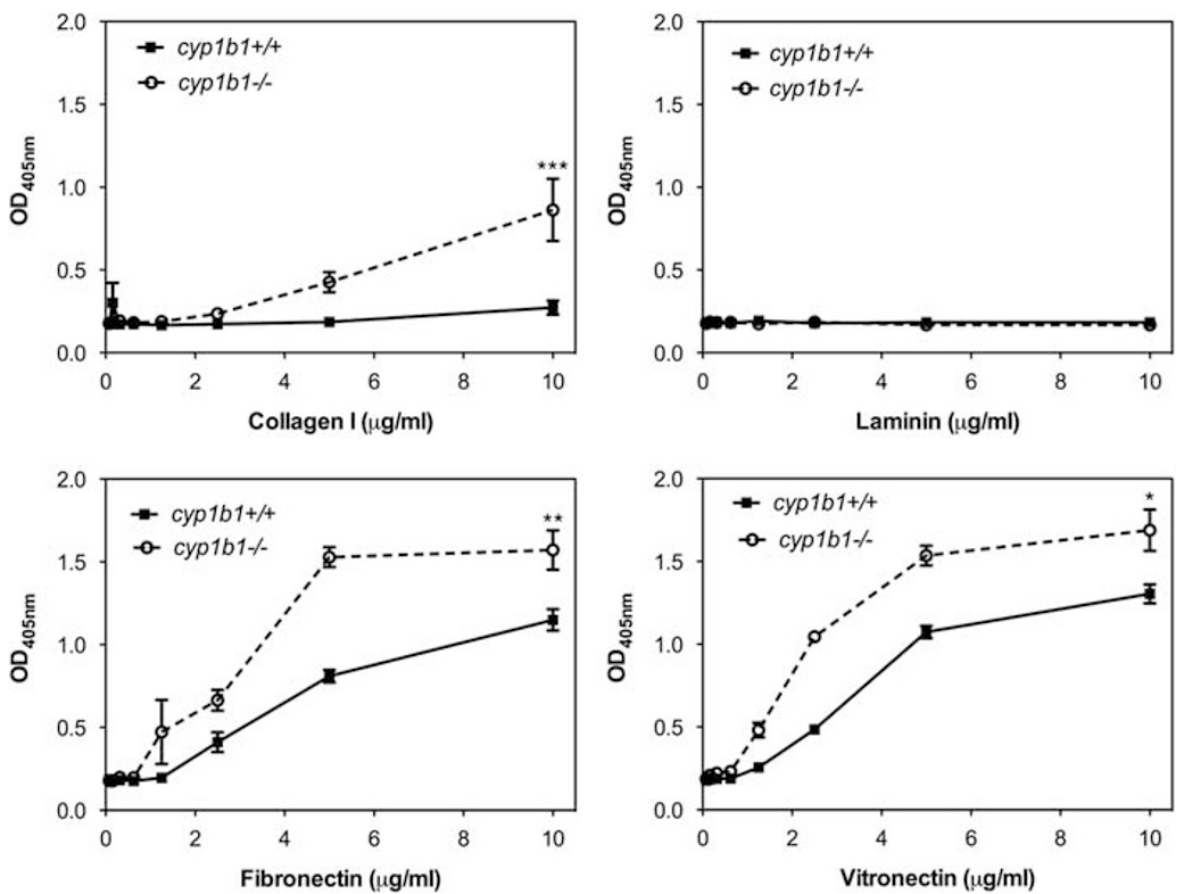

Figure 6 Cyp $1 b 1-/$ - retinal (PC) are more adherent. Adhesion of cyp $1 b 1+/+$ and cyp $1 b 1-/-$ PC to vitronectin, laminin, fibronectin and collagen I was determined as described in Experimental Procedures. Please note an increase in adhesion of cyp $1 \mathrm{~b} 1-/-P C$ to collagen I (***P<0.0001), fibronectin $(* * P=0.0021)$, and vitreonectin $(* P=0.021)$.

results is shown in Figure 7b. A 50\% decrease in $\alpha 5$ and a $70 \%$ decrease in $\alpha 7$ integrin levels were observed.

\section{Alterations in Production of ECM Proteins in cyp1b1 - /- PC}

The extracellular matrix serves many functions, including providing support, regulating the dynamic behavior of a cell, and acting as a depot for various cellular growth and soluble factors. Fibronectin, osteopontin, tenascin- $\mathrm{C}$ and thrombospondins are constituents of the ECM with significant roles in tissue remodeling and repair, cell migration and vascular inflammation. We examined the production of various ECM proteins in cyplb1+/+ and cyp $1 b 1-/-$ PC by western blot analysis of conditioned medium and cell lysates (Figure 8a). Figure $8 \mathrm{~b}$ shows the quantitative evaluation of the data. A three- and four-fold increase in the amount of TSP2 was detected in both lysate and conditioned medium of cyp $1 b 1-/-$ PC compared with cyp $1 b 1+/+$ PC, respectively. We observed a $60 \%$ reduction in the secretion of TSP 1 and an $80 \%$ decrease in the secretion of tenascin- $\mathrm{C}$ in the conditioned medium of cyp1b1-/- PC compared with cyp $1 b 1+/+$ cells. Osteopontin expression in both cell lysate and conditioned medium was undetectable in cyp $1 b 1-/-$ PC compared with wild-type cells.

\section{Alterations in Intracellular Signaling Pathways of cyp1b1-/- PC}

The mitogen activated protein kinases (MAPK), including ERK1/2, regulate a diverse range of processes including cell proliferation, adhesion, and apoptosis. The Jun $\mathrm{N}$-terminal Kinase (JNK) family has crucial roles in regulating cell stress, inflammation and apoptosis. Similar to JNK, the p38 MAPK cascade also responds to cell stress and inflammatory cytokines. Akt, a serine/threonine-specific kinase, is a regulator of multiple downstream processes, including glucose metabolism, apoptosis, cell proliferation, and migration. We assessed whether there were perturbations in any of these signaling pathways in cyp1b1-/- PC. Both cell types exhibited similar phosphorylation and total p38, JNK, and Erk1/2 (Figure 9a). We observed an increase in phospho-Akt in cyp1b1-/- PC compared with cyp1b1+/+ PC (Figure 9b). This is consistent with their reduced rate of apoptosis.

NF- $\kappa \mathrm{B}$ proteins comprise a family of transcription factors that are involved in the control of a large number of cellular processes such as immune and inflammatory responses, cellular growth and apoptosis. ${ }^{36,37}$ These transcription factors are persistently active in a number of disease states, including cancer, chronic inflammation, glaucoma, retinal diseases, and diabetes. $^{38-40}$ Increased oxidative stress can activate NF- $\kappa$ B signaling in cells. ${ }^{41-43}$ To delineate whether a Cyp1B1 deficiency functionally impacts NF- $\kappa \mathrm{B}$ signaling, we measured the level of phosphorylated and total p65 NF- $\kappa \mathrm{B}$. We observed a 1.5-fold increase in phospho-p65 and a 2.5fold increase in total p65 expression in cyp1b1-/- PC (Figure $9 \mathrm{c}$ and $\mathrm{d}$ ). We analyzed several NF- $\kappa \mathrm{B}$ target genes to confirm constitutive activation of the NF- $\kappa \mathrm{B}$ pathway in the cyp1b1-/ - PC. We confirmed a 3.5-fold and a 2.5 -fold 
a
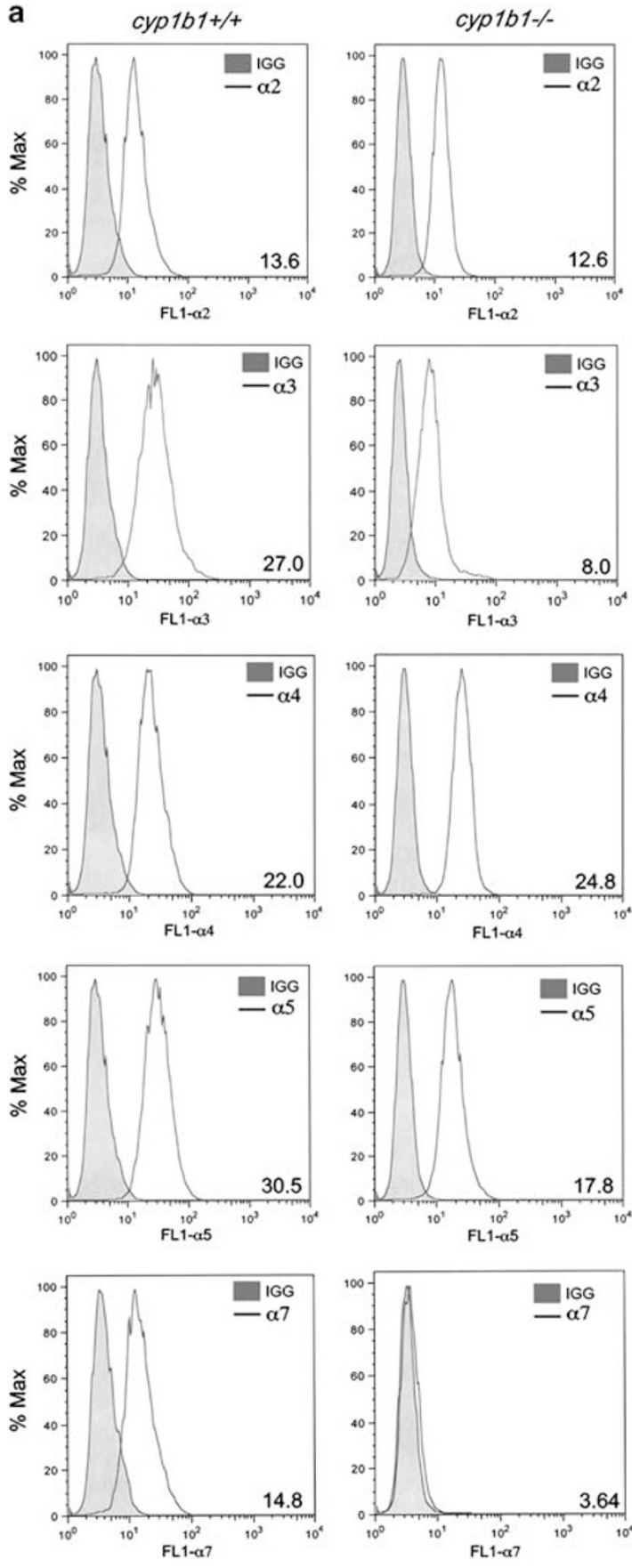

b

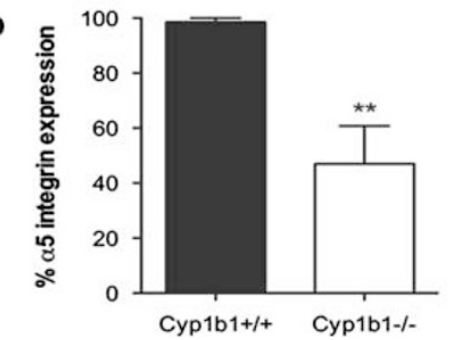

cyp1b1\%
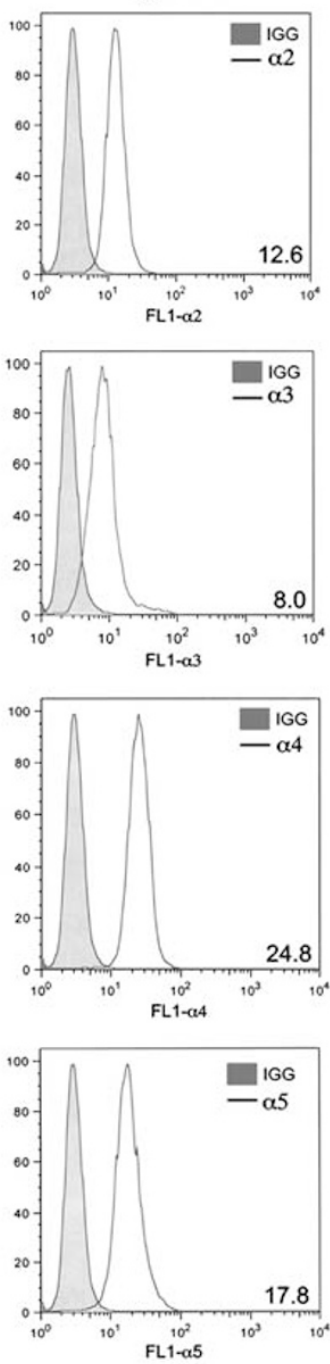
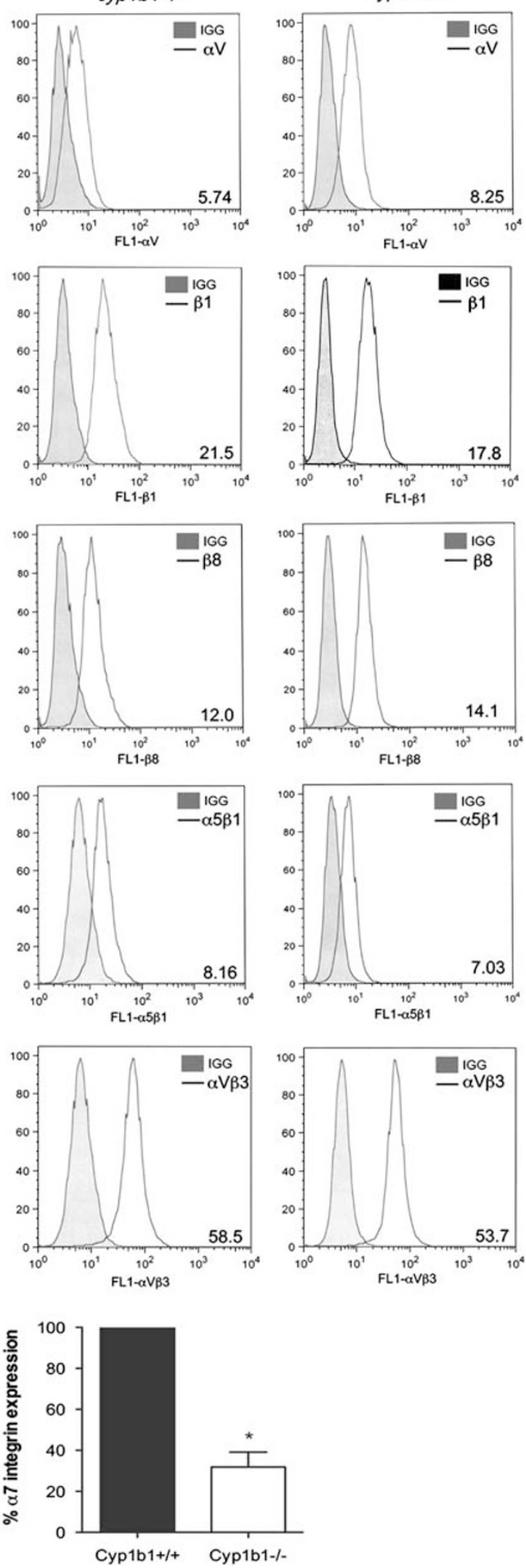

Figure 7 Cyp 161 - / - retinal pericytes (PC) exhibit altered expression of integrins. (a) Expression of $\alpha 1, \alpha 2, \alpha 3, \alpha 4, \alpha 5, \alpha 7, \alpha \mathrm{V}, \beta 1, \beta 8, \alpha 5 \beta 1$, and $\alpha \mathrm{V} \beta 3$ integrins in cyp $1 b 1+/+$ and cyp $1 b 1-/-P C$ was determined by flow cytometry using specific antibodies as described in Materials and Methods. The shaded traces show staining in the absence of primary antibody. Representative mean fluorescent intensities are indicated in the bottom right corner of each panel. (b) Percent expression of $\alpha 5$ and $\alpha 7$ integrins was determined $\left(N=3,{ }^{*} P<0.05,{ }^{* *} P<0.01\right)$. 


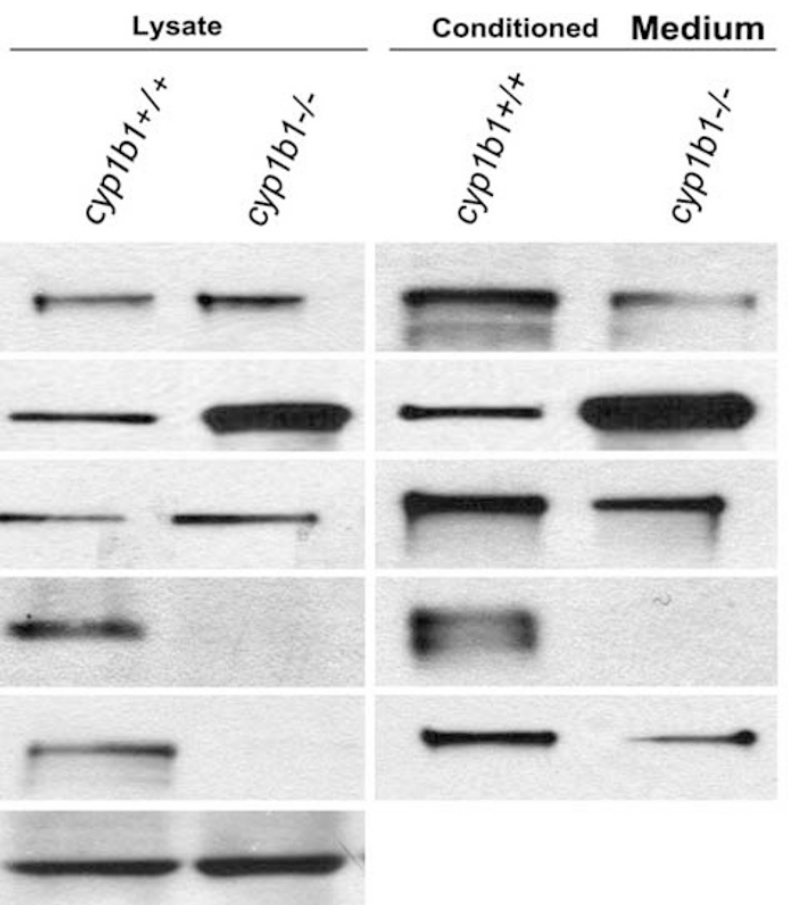

b
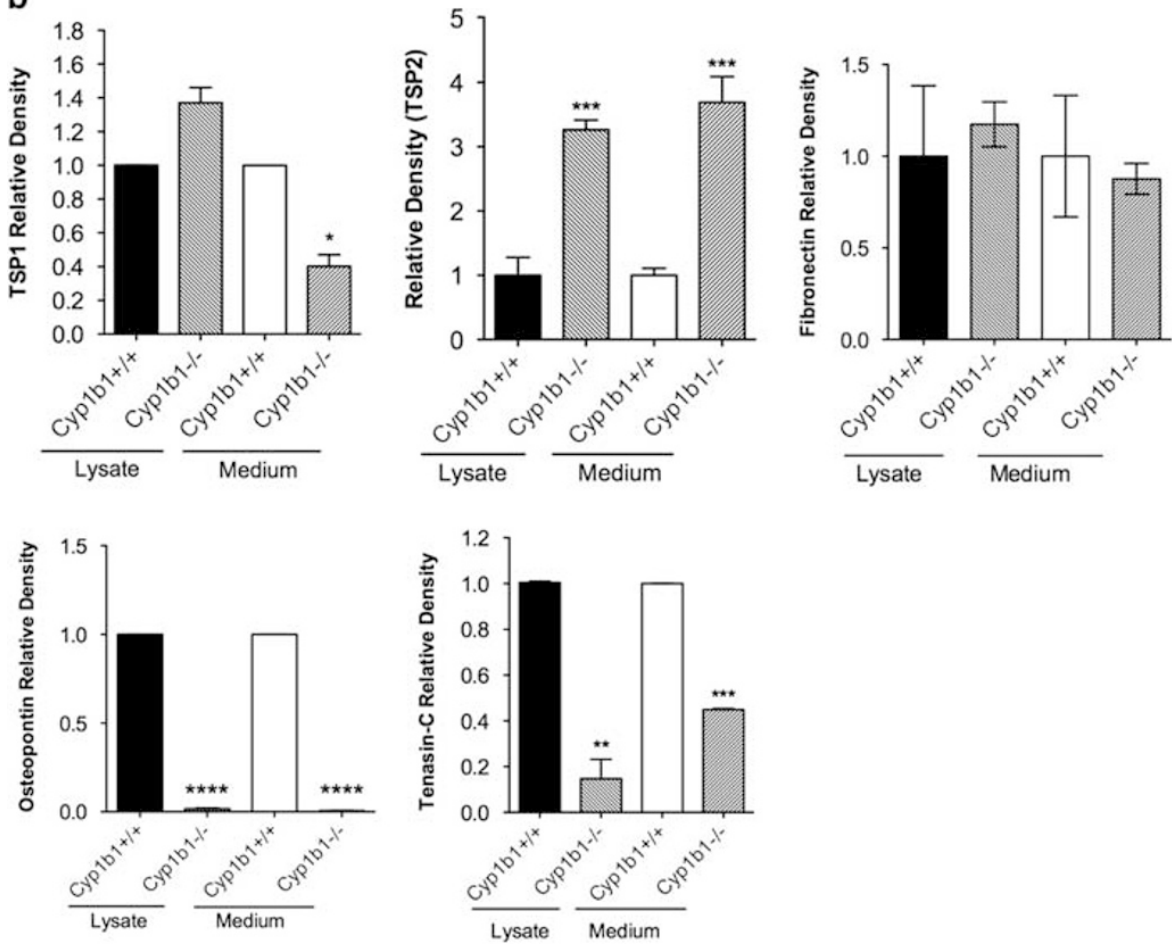

Figure 8 Altered expression of ECM proteins in cyp $1 b 1$ - / - retinal pericytes (PC). (a) Cyp $1 b 1+/+$ and cyp $1 b 1-/-$ PC were incubated for 2 days with serum-free PC medium. Cell lysates and conditioned medium were analyzed by western blot analysis for TSP1, TSP2, fibronectin, osteopontin, and tenascin-C using specific antibodies as described in Materials and Methods. (b) Quantitative assessment of band intensity was determined $(N=3$, $\left.{ }^{*} P<0.05,{ }^{* *} P<0.001,{ }^{* * *} P<0.0001,{ }^{* * *} P<0.00001\right)$.

increase in NF- $\kappa \mathrm{B}$ target gene mRNA for monocyte chemoattractant protein-1 (MCP-1) and tumor necrosis factoralpha (TNF- $\alpha$ ), two major inflammatory mediators produced by $\mathrm{PC}$, respectively. ${ }^{44}$

\section{Loss of Cyp1B1 Alters Capillary Morphogenesis and VEGF Secretion in PC}

Stabilization of patent vessels is a critical function of PC. ${ }^{29,35}$ We next investigated the impact a lack of Cyp1B1 has on the 
a
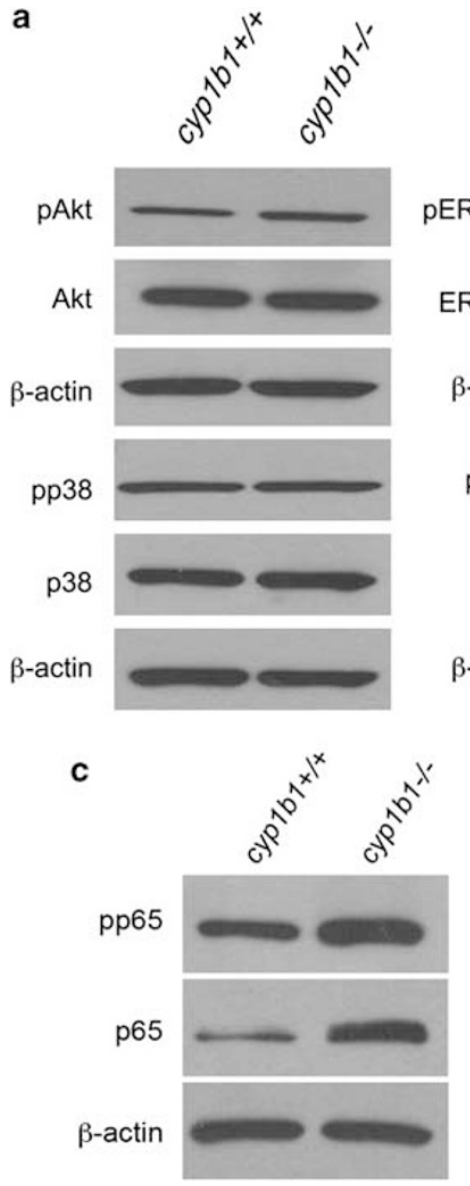

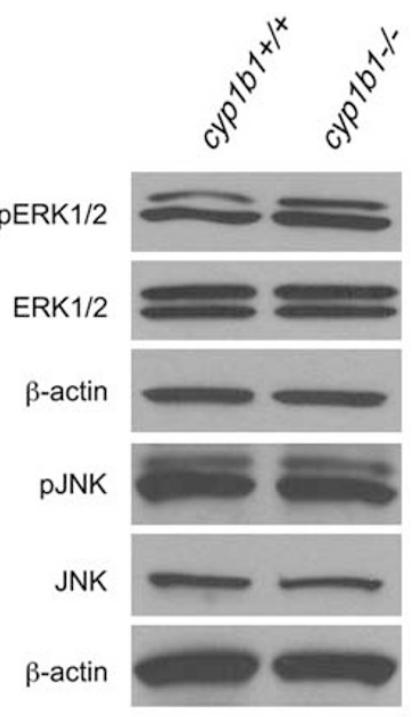

b
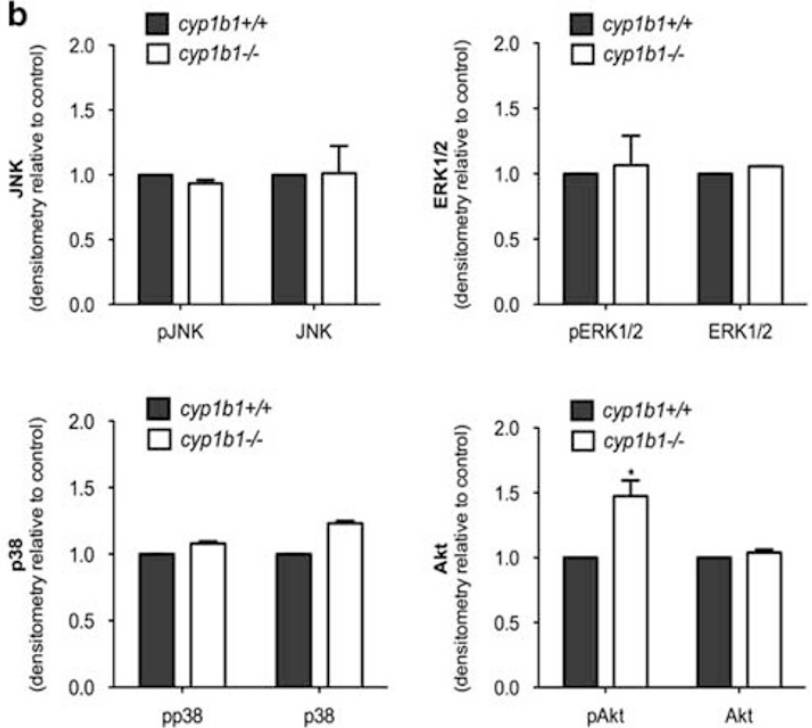

d
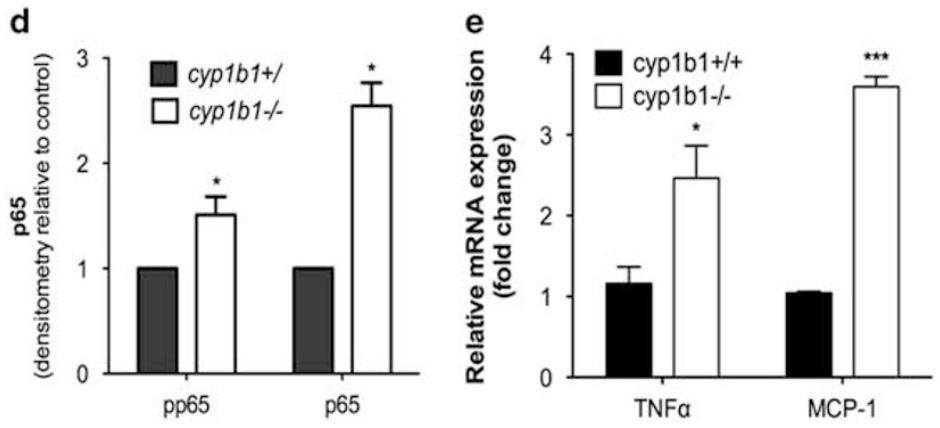

Figure 9 Alterations in cellular signaling pathways in cyp $1 b 1-/$ - retinal pericytes (PC). (a) Cyp $1 b 1+/+$ and cyp $1 b 1-/-\mathrm{PC}$ were analyzed by western blot analysis for expression of phospho-Akt, total Akt, phospho-p38, total p38, phospho-Erk1/2, total Erk1/2, phospho-JNK, total JNK, and $\beta$-actin. (b) Quantification of band intensity demonstrated a 1.5 -fold increase in phospho-Akt $(N=3, * P<0.05)$. (c) Levels of phospho-p65 NF- $\kappa$ B, total p65, and $\beta$-actin were determined by western blotting. (d) Quantitative assessment of the data $\left(N=3,{ }^{*} P<0.05\right)$. (d,e) Levels of RNA were assessed for NF- $\kappa$ B target genes MCP-1 (***P $\leq 0.0001)$ and TNF $\alpha\left({ }^{*} P<0.05\right)$.

ability of retinal EC to undergo capillary morphogenesis. We have previously shown that a loss of Cyp1B1 in retinal EC attenuates capillary morphogenesis. ${ }^{14,27}$ In Figure $10 \mathrm{a}-\mathrm{h}$, we show that a lack of Cyp1B1 affects the co-culture of retinal $\mathrm{EC}$ and PC. Panels $\mathrm{c}$ and $\mathrm{d}$ show that PC do not form a tubelike network when plated alone in Matrigel. Together, retinal EC and PC (e) form a substantially improved tubular network compared with wild-type EC alone (a, ${ }^{\star} P<0.05$, comparison not indicated on graph). Co-culture of wild-type retinal EC with cyp1b1-/ - PC showed a 50\% decrease in tube formation (g) compared with control (e). In contrast, cyp1b1 - / - retinal EC cultured with wild-type PC (h) displayed improved tube formation over the co-culture of cyp1b1-/ - retinal EC and cyp1b1-/ - PC (f). Through cell-to-cell contact and/or the secretion of multiple factors, the expression of Cyp1B1 is essential for capillary morphogenesis in vitro. The quantitative assessment of the mean number of branch points per field is shown in Figure 10i.

VEGF is a well-recognized inducer of angiogenesis. PC in the vasculature secrete VEGF to promote the survival of the endothelium. ${ }^{45}$ We assessed whether secretion of VEGF into the medium was altered in the absence of Cyp1B1. A 2.2-fold decrease in VEGF levels was observed in cyp1b1-/- PC compared with cyp1b1+/+ PC (Figure 10j).

Mechanistically, signal transducers and activators of transcription (STAT), mainly STAT3, have an important role during angiogenesis, in both physiological and pathological conditions affecting cell survival, proliferation, inflammation, and oncogenesis. STAT3 participates in angiogenesis, in part, through the modulation of VEGF expression. We determined whether lack of Cyp1B1 impacted STAT3 phosphorylation (Figure 10k). We observed a fourfold decrease in the level of phosphorylated STAT3 in cyp1b1-/- PC compared with wild-type PC (Figure 101). Thus, decreased signaling through the STAT3 pathway may be responsible for attenuation of VEGF expression in cyp1b1-/- PC.

\section{DISCUSSION}

PC are essential components of blood vessels, and are necessary for proper development, homeostasis, and organ 

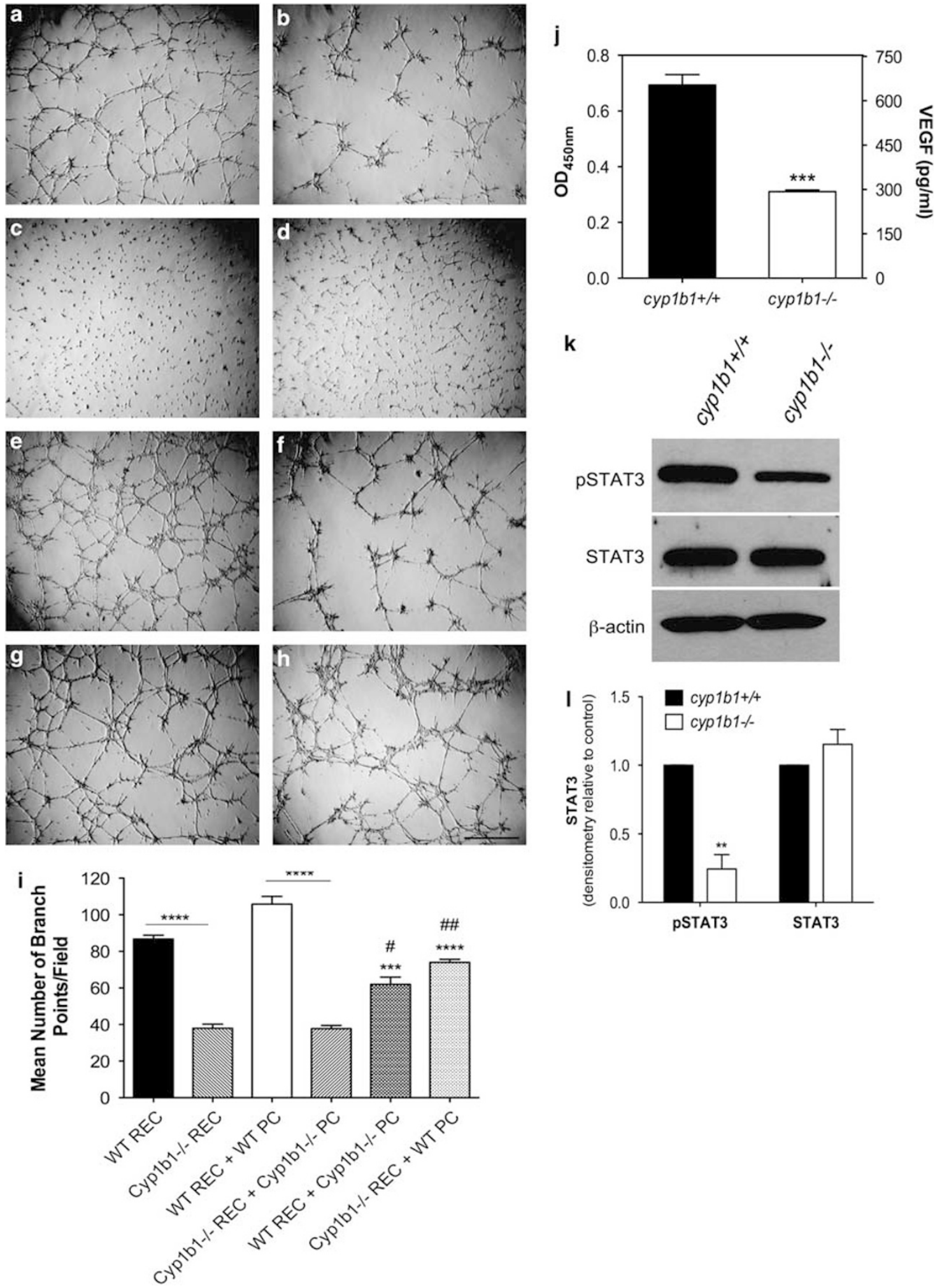

Figure 10 Loss of Cyp1B1 alters capillary morphogenesis and the production of vascular endothelial growth factor (VEGF) through the STAT3 pathway. $(\mathbf{a}-\mathbf{h})$ Capillary morphogenesis of retinal endothelial cell (EC) and pericytes (PC) was assessed by co-culturing cells in Matrigel for $18 \mathrm{~h}$. Representative images are shown; (a) wild-type retinal EC, (b) cyp1b1 - / - PC, (c) wild-type PC, (d) cyp1b1 - / - PC, (e) wild-type retinal EC + PC, (f) Cyp1b1 - / retinal EC + cyp1b1-/- PC, (g) wild-type retinal EC + cyp1b1-/- PC, (h) Cyp1b1-/ - retinal EC + wild-type PC. Scale bar represents $500 \mu$ m. (i) Mean number of branch points were counted $\left(N=3,{ }^{* * *} P<0.0001,{ }^{* * * *} P<0.00001\right)$. (j) Analysis of VEGF levels in cyp $1 b 1+/+$ and cyp $1 b 1-/-$ PC demonstrated a twofold decrease ( $\left.{ }^{* *} P \leq 0.0001\right)$. (k) Levels of phospho-STAT3, total STAT3, and $\beta$-actin were determined by Western blotting. (l) Quantification of band intensity demonstrated a fourfold decrease in PSTAT3 $\left(N=3,{ }^{* *} P<0.001\right)$. 
function. ${ }^{28,29}$ Alterations in PC recruitment, density, and attachment to the endothelium are associated with many vasculopathies, including diabetic retinopathy and hereditary stroke. ${ }^{4}$ We recently showed that Cyp1B1 is constitutively expressed in EC from vascular beds of various tissues including retina, and has an important role in the regulation of the angiogenic properties of EC in culture and neovascularization in vivo. ${ }^{14,27}$ Here we demonstrated that Cyp1B1 is constitutively expressed in retinal, heart and kidney PC and is further induced by TCDD, a known inducer of Cyp1B1 (Figure 1b and c). We showed that lack of Cyp1B1 was associated with enhanced proliferation and reduced apoptosis of PC. In addition, Cyb1b1 - / - PC exhibited increased oxidative stress and sustained activation of NF- $\kappa \mathrm{B}$ p65. These cells also exhibited significant defects in their adhesion and migration, concomitant with alterations in expression of various ECM proteins and their receptors. Together, our results suggest that Cyp1B1 expression and/or activity is essential for maintaining the cellular reductive state with significant impact on PC function.

Consistent and unequivocal identification of PC is challenging due to the heterogeneity of the PC population from different vascular bed sources and the isolation at different developmental stages. The multiple markers applied in Figures 1 and 2 to identify PC are neither specific nor stable in their expression, however, we observed expression of classical PC markers PDGFR- $\beta$, NG2, and $\alpha$ SMA. The heterogeneity in retinal PC was confirmed by expression of NG2 and $\alpha$ SMA in Figure 1e. Immunofluorescent staining revealed uniform, but relatively low expression of PDGFR- $\beta$ (not shown), which may partially be due to low binding affinity of the antibody in this method or due to the limitation that not all PC express high levels of PDGFR- $\beta .{ }^{46}$

We also demonstrated that a loss of Cyp1B1 in PC resulted in increased proliferation concomitant with a decreased rate of apoptosis, both under basal and challenged conditions. The reduced rate of apoptosis may be attributed, at least in part, to the decreased expression of $\mathrm{Bax}$ and Bim, pro-apoptotic members of the Bcl-2 family, observed in the Cyp1B1-deficient cells. However, it is also possible that the increased phosphorylation of serine/threonine-specific Akt1 may contribute to the overall survival of PC in the Cyp1B1-deficient cells.

Oxidative stress occurs as a consequence of inequity between pro-and antioxidant systems, causing injury to biomolecules, such as nucleic acids, proteins, structural carbohydrates, and lipids. Polyunsaturated fatty acids are especially susceptible to peroxidation to form lipid peroxyl radicals. Peroxidation of lipids disturbs the assembly of membranes, leading to changes in permeability, alterations in ion transport and injury to mitochondria, which further potentiates ROS generation. We previously showed increases in 4-hydroxynonenal staining in retinas of cyp1b1-/ - mice compared with wild-type mice. ${ }^{14}$ Here we showed that cyp1b1-/ - PC produce markedly more ROS than cyp $1 b 1+/+$ PC, similar to our previously reported results in EC. ${ }^{14}$ Inhibition of Cyp1B1 enzymatic activity by incubation of TMS with cyp1b1+/+ PC also resulted in higher levels of ROS compared with control cells. Furthermore, incubation of cyp1b1-/- PC with antioxidant NAC, lowered ROS levels. Cyp1B1 may influence the oxidative metabolism of endogenous substrates and maintain the cellular reductive state. Furthermore, a lack of Cyp1B1 expression and/or activity leads to the accumulation of ROS and increased oxidative stress in PC. Although the exact identity of the reactive species remains elusive, we believe these are oxygenated products of polyunsaturated fatty acids, which are normally metabolized by Cyp1B1 relieving intracellular oxidative stress.

NF- $\kappa \mathrm{B}$ is a redox-sensitive transcription factor ${ }^{47}$ with a central role in inflammation and is activated by increased intracellular oxygenated products. We observed increases in total p65 protein expression concomitant with increased p65 phosphorylation in cyp1b1-/- PC. To confirm activation of NF- $\kappa \mathrm{B}$ signaling, we investigated mRNA expression of two target genes, MCP- 1 and TNF- $\alpha$. Expression of these genes was increased in Cyp1B1-null PC compared with control cells. Pharmacological inhibitors and dominant-negative inhibition of NF- $\kappa \mathrm{B}$ signaling are currently being investigated in our laboratory to further delineate the contribution of constitutive NF- $\kappa \mathrm{B}$ activation to the Cyp1b1-null phenotype, both in vitro and in vivo.

The production of PDGF-BB by EC is essential for the recruitment of PC to newly forming microvessels. ${ }^{35}$ The expression of PDGFR- $\beta$ on the surface of PC is required for paracrine signaling and immediate attraction to emerging angiogenic sprouts. We observed a significant increase in the basal migration of cyplb1-/- PC. These changes in migration may be ancillary to altered adhesion to ECM proteins, fibronectin and vitronectin in cyp $1 b 1-/-\mathrm{PC}$, and activation of downstream signaling pathways. The changes in adhesion may be attributed, in part, to the changes in integrin expression and/or activity in these cells. Although we observed similar levels of $\alpha 5 \beta 1$ and $\alpha \mathrm{v} \beta 3$-integrin expression (major fibronectin and vitronectin receptors), $\alpha 5$ and $\alpha 7$ integrin expression was decreased. Integrin $\alpha 7$ has an important role in vascular development and integrity, and its loss is responsible for alterations in vascular remodeling and increased proliferation of VSMC. ${ }^{48,49}$ The reduced expression of $\alpha 7$ integrin is consistent with increased proliferation of cyp1b1-/- PC and may contribute in a complex manner to the overall increase in survival observed here. We also observed that loss of Cyp1B1 in PC resulted in a dramatic upregulation of both cell associated and secreted TSP2. We previously showed that the loss of Cyp1B1 in EC results in increased expression of TSP2, a matricellular protein with anti-angiogenic activity. ${ }^{14}$ In comparison, however, expression of TSP2 in retinal EC is significantly lower than that expressed in PC. The role TSP2 has in PC function is currently unknown. Together, our results suggest that Cyp1B1 expression is critical to the physiological 
functions of PC including adhesion, proliferation, migration, and recruitment to newly forming microvessels.

Interactions between EC and PC are important in blood vessel maturation and stabilization. ${ }^{29}$ Changes in cell-cell interactions are mediated through $\alpha 4 \beta 1$-integrin on proliferating EC and VCAM-1 in proliferating PC. ${ }^{50}$ The antagonism of these interactions prevents the adhesion of PC to the endothelium, resulting in EC dysfunction and dysregulation of angiogenesis. We observed a significant decrease in the expression of VCAM-1 in cyp1b1 - / - PC. A lack of Cyp1B1 may significantly hamper EC and PC interactions, and impede angiogenesis. ${ }^{14}$ We observed disruptions in capillary morphogenesis using co-culture methods. Loss of Cyp1B1 in PC resulted in attenuation of EC capillary morphogenesis. In contrast, wild-type PC restored capillary morphogenesis of cyp1b1-/ - retinal EC. This suggests that through cell-cell interaction and/or the secretion of soluble mediators, Cyp1B1 is essential for the development, maturation, and stabilization of the vasculature. PC influence vessel stability by ECM deposition, production, and release of soluble factors that promote endothelial quiescence. Alterations in the production of the ECM may modulate EC and PC proliferation and migration and lead to defects in vascular stability. We observed a decrease in secreted TSP1 and tenascin-C from $c y p 1 b 1-/-$ PC. Expression of cell associated and secreted osteopontin was also undetectable compared with wild-type cells. Osteopontin is involved in inflammatory cell migration, differentiation of osteoclasts and inflammatory cytokine production. ${ }^{51-54}$ Knockdown of osteopontin leads to the amelioration of autoimmune arthritis and tumor metastasis. Phosphorylation of osteopontin is required for its ability to inhibit VSMC calcification. ${ }^{55} \mathrm{~A}$ binding site exists in osteopontin for $\alpha 4 \beta 1$ integrin. Alteration in ECM production in cyp1b1-/- PC, along with aberrant VCAM-1 expression, may lead to the observed aberrant EC and PC interactions in vitro and attenuation of angiogenesis in vivo.

Retinal vascularization is a highly orchestrated process that is coordinated through complex interactions among EC, PC, and astrocytes, and is tightly regulated by a balanced production of pro- and anti-angiogenic factors. ${ }^{56,57}$ VEGF is one of the most important mediators of ocular angiogenesis. Production of VEGF by PC is important for survival of EC and vascular integrity. ${ }^{45}$ Cyp $1 b 1-/-$ PC exhibited a two-fold decrease in VEGF production. Decreased VEGF production was consistent with enhanced migration and proliferation of PC. Greenberg et $a l^{58}$ recently showed that VEGF may act as a negative regulator of PC function and vessel maturation. Increasing studies show that STAT3 participates in regulating angiogenesis, largely in part, through modulation of VEGF expression..$^{59}$ STAT3 is a direct transcriptional activator of the VEGF gene by binding to the VEGF promoter. ${ }^{60}$ Activated STAT3 upregulates VEGF expression, and promotes tumor angiogenesis. ${ }^{60} \mathrm{We}$ observed a significant decrease in the level of STAT3 serine 727 phosphorylation in cyplb1-/- PC. Decreased production of VEGF by cyp1b1-/- PC may contribute to the EC dysfunction and attenuation of neovascularization we previously reported in cyp $1 b 1-/-$ mice.

In summary, we demonstrated in retinal PC that expression and/or activity of Cyp1B1 is essential for the appropriate proliferation and migration of PC and subsequent interactions with the underlying endothelium. Cyp1B1 deficiency in $\mathrm{PC}$ resulted in increased oxidative stress, sustained activation of NF- $\kappa \mathrm{B}$, increased expression of TSP2, and decreased expression of VEGF. Together, our results indicate that the expression of Cyp1B1 is essential for maintaining the cellular reductive state and normal PC function.

\section{ACKNOWLEDGEMENTS}

We thank Dr Zafer Gurel and SunYoung Park for their assistance in conducting experiments. This work supported in part by NIH grants T32 ES007015, EY016995, EY018179, RC4 EY021357, P30 CA014520 University of Wisconsin Paul P. Carbone Cancer Center Support grant, P30 EY016665, and an unrestricted departmental award from Research to Prevent Blindness. NS is a recipient of a Research Award from American Diabetes Association (1-20-BS-160) and Retina Research Foundation. TLP is recipient of a Kirschstein-NRSA Fellowship Award (F31 EY021091) and a Science and Medicine Graduate Research Scholar at the University of Wisconsin-Madison.

\section{DISCLOSURE/CONFLICT OF INTEREST}

The authors declare no conflict of interest.

1. Hellstrom $M$, Kalen $M$, Lindahl $P$, et al. Role of PDGF-B and PDGFR-beta in recruitment of vascular smooth muscle cells and pericytes during embryonic blood vessel formation in the mouse. Development 1999;126:3047-3055.

2. Rolny C, Nilsson I, Magnusson $P$, et al. Platelet-derived growth factor receptor-beta promotes early endothelial cell differentiation. Blood 2006;108:1877-1886.

3. von Tell D, Armulik A, Betsholtz C. Pericytes and vascular stability. Exp Cell Res 2006;312:623-629.

4. Hayden MR, Yang Y, Habibi J, et al. Pericytopathy: Oxidative stress and impaired cellular longevity in the pancreas and skeletal muscle in metabolic syndrome and type 2 diabetes. Oxid Med Cell Longev 2010;3:290-303.

5. Fleming I. Vascular cytochrome p450 enzymes: physiology and pathophysiology. Trends Cardiovasc Med 2008;18:20-25.

6. Coon MJ. Cytochrome P450: nature's most versatile biological catalyst. Annu Rev Pharmacol Toxicol 2005;45:1-25.

7. Stoilov I, Rezaie T, Jansson I, et al. Expression of cytochrome P4501b1 (Cyp1b1) during early murine development. Mol Vis 2004;10:629-636.

8. Murray Gl, Melvin WT, Greenlee WF, et al. Regulation, function, and tissue-specific expression of cytochrome P450 CYP1B1. Annu Rev Pharmacol Toxicol 2001;41:297-316.

9. Hakkola J, Pasanen M, Pelkonen O, et al. Expression of CYP1B1 in human adult and fetal tissues and differential inducibility of CYP1B1 and CYP1A 1 by Ah receptor ligands in human placenta and cultured cells. Carcinogenesis 1997;18:391-397.

10. Choudhary D, Jansson I, Rezaul K, et al. Cyp1b1 protein in the mouse eye during development: an immunohistochemical study. Drug Metab Dispos 2007;35:987-994.

11. Bejjani $B A, X u L$, Armstrong $D$, et al. Expression patterns of cytochrome P4501B1 (Cyp1b1) in FVB/N mouse eyes. Exp Eye Res 2002;75: 249-257.

12. Ikegwuonu $\mathrm{Fl}$, Christou M, Jefcoate CR. Regulation of cytochrome P4501B1 (CYP1B1) in mouse embryo fibroblast (C3H10T1/2) cells by protein kinase C (PKC). Biochem Pharmacol 1999;57:619-630.

13. Zhang L, Savas U, Alexander DL, et al. Characterization of the mouse Cyp1B1 gene. Identification of an enhancer region that directs aryl hydrocarbon receptor-mediated constitutive and induced expression. J Biol Chem 1998;273:5174-5183.

14. Tang Y, Scheef EA, Wang S, et al. CYP1B1 expression promotes the proangiogenic phenotype of endothelium through decreased 
intracellular oxidative stress and thrombospondin-2 expression. Blood 2009;113:744-754.

15. Sutter TR, Tang $\mathrm{YM}$, Hayes $\mathrm{CL}$, et al. Complete CDNA sequence of a human dioxin-inducible mRNA identifies a new gene subfamily of cytochrome P450 that maps to chromosome 2. J Biol Chem 1994;269:13092-13099.

16. Kerzee JK, Ramos KS. Constitutive and inducible expression of Cyp1a1 and Cyp1b1 in vascular smooth muscle cells: role of the Ahr bHLH/PAS transcription factor. Circ Res 2001;89:573-582.

17. Heidel SM, Czuprynski CJ, Jefcoate CR. Bone marrow stromal cells constitutively express high levels of cytochrome P4501B1 that metabolize 7,12-Dimethylbenz[a]anthracene. Mol Pharmacol 1998;54:1000-1006.

18. Eltom SE, Zhang L, Jefcoate CR. Regulation of cytochrome P-450 (CYP) 1B1 in mouse Hepa-1 variant cell lines: a possible role for aryl hydrocarbon receptor nuclear translocator (ARNT) as a suppressor of CYP1B1 gene expression. Mol Pharmacol 1999;55:594-604.

19. Eltom $S E$, Larsen $M C$, Jefcoate CR. Expression of CYP1B1 but not CYP1A1 by primary cultured human mammary stromal fibroblasts constitutively and in response to dioxin exposure: role of the Ah receptor. Carcinogenesis 1998;19:1437-1444.

20. Conway DE, Sakurai $Y$, Weiss $D$, et al. Expression of CYP1A1 and CYP1B1 in human endothelial cells: regulation by fluid shear stress. Cardiovasc Res 2009;81:669-677.

21. Brake PB, Arai M, As-Sanie $\mathrm{S}$, et al. Developmental expression and regulation of adrenocortical cytochrome P4501B1 in the rat Endocrinology 1999;140:1672-1680.

22. Buters JT, Sakai S, Richter T, et al. Cytochrome P450 CYP1B1 determines susceptibility to 7,12-dimethylbenz[a]anthracene-induced lymphomas. Proc Natl Acad Sci USA 1999;96:1977-1982.

23. Choudhary D, Jansson I, Stoilov I, et al. Metabolism of retinoids and arachidonic acid by human and mouse cytochrome P450 1b1. Drug Metab Dispos 2004;32:840-847.

24. Stoilov I, Akarsu AN, Sarfarazi M. Identification of three different truncating mutations in cytochrome P4501B1 (CYP1B1) as the principal cause of primary congenital glaucoma (Buphthalmos) in families linked to the GLC3A locus on chromosome 2 p21. Hum Mol Genet 1997;6:641-647.

25. Bejjani BA, Lewis RA, Tomey KF, et al. Mutations in CYP1B1, the gene for cytochrome P4501B1, are the predominant cause of primary congenital glaucoma in Saudi Arabia. Am J Hum Genet 1998;62:325-333.

26. Libby RT, Smith RS, Savinova OV, et al. Modification of ocular defects in mouse developmental glaucoma models by tyrosinase. Science 2003:299:1578-1581.

27. Tang Y, Scheef EA, Gurel Z, et al. CYP1B1 and endothelial nitric oxide synthase combine to sustain proangiogenic functions of endothelial cells under hyperoxic stress. Am J Physiol Cell Physiol 2010;298:C665-C678.

28. Hirase T, Node K. Endothelial dysfunction as a cellular mechanism for vascular failure. Am J Physiology-Heart Circulatory Physiol 2012;302:H499-H505.

29. Armulik A, Genove G, Betsholtz C. Pericytes: developmental, physiological, and pathological perspectives, problems, and promises. Dev Cell 2011;21:193-215.

30. DiMaio TA, Sheibani N. PECAM-1 isoform-specific functions in PECAM1-deficient brain microvascular endothelial cells. Microvasc Res 2008;75:188-201.

31. Zhao W, Parrish AR, Ramos KS. Constitutive and inducible expression of cytochrome P450IA1 and P450IB1 in human vascular endothelial and smooth muscle cells. In Vitro Cell Dev Biol Anim 1998;34:671-673.

32. Gibson P, Gill JH, Khan PA, et al. Cytochrome P450 1B1 (CYP1B1) is overexpressed in human colon adenocarcinomas relative to normal colon: implications for drug development. Mol Cancer Ther 2003;2:527-534.

33. Wang $X Q$, Lindberg $F P$, Frazier WA. Integrin-associated protein stimulates alpha2beta1-dependent chemotaxis via Gi-mediated inhibition of adenylate cyclase and extracellular-regulated kinases. J Cell Biol 1999;147:389-400.

34. Scheef EA, Sorenson CM, Sheibani N. Attenuation of proliferation and migration of retinal pericytes in the absence of thrombospondin-1. Am J Physiol Cell Physiol 2009;296:C724-C734.

35. Armulik A, Abramsson A, Betsholtz C. Endothelial/pericyte interactions. Circ Res 2005;97:512-523.
36. Perkins ND. Integrating cell-signalling pathways with NF-kappaB and IKK function. Nat Rev Mol Cell Biol 2007;8:49-62.

37. Tabruyn SP, Griffioen AW. NF-kappaB: a new player in angiostatic therapy. Angiogenesis 2008;11:101-106.

38. Partridge $\mathrm{J}$, Carlsen $\mathrm{H}$, Enesa $\mathrm{K}$, et al. Laminar shear stress acts as a switch to regulate divergent functions of NF-kappaB in endothelial cells. FASEB J. 2007;21:3553-3561.

39. Romeo G, Liu WH, Asnaghi V, et al. Activation of nuclear factor-kappaB induced by diabetes and high glucose regulates a proapoptotic program in retinal pericytes. Diabetes 2002;51:2241-2248.

40. Xu C, Shen G, Chen C, et al. Suppression of NF-kappaB and NF-kappaBregulated gene expression by sulforaphane and PEITC through IkappaBalpha, IKK pathway in human prostate cancer PC-3 cells. Oncogene 2005;24:4486-4495.

41. Bonello S, Zahringer C, BelAiba RS, et al. Reactive oxygen species activate the HIF-1alpha promoter via a functional NFkappaB site. Arterioscler Thromb Vasc Biol 2007;27:755-761.

42. Donato AJ, Eskurza I, Silver $A E$, et al. Direct evidence of endothelial oxidative stress with aging in humans: relation to impaired endothelium-dependent dilation and upregulation of nuclear factorkappaB. Circ Res 2007;100:1659-1666.

43. Kowluru RA, Koppolu P, Chakrabarti S, et al. Diabetes-induced activation of nuclear transcriptional factor in the retina, and its inhibition by antioxidants. Free Radic Res 2003;37:1169-1180.

44. Nehmé A, Edelman J. Dexamethasone inhibits high glucose-, TNF- $\alpha-$, and IL-1 $\beta$-induced secretion of inflammatory and angiogenic mediators from retinal microvascular pericytes. Invest Ophthalmol Vis Sci 2008;49:2030-2038.

45. Darland DC, Massingham $\mathrm{U}$, Smith SR, et al. Pericyte production of cell-associated VEGF is differentiation-dependent and is associated with endothelial survival. Dev Biol 2003;264:275-288.

46. Song S, Ewald AJ, Stallcup W, et al. PDGFRbeta + perivascular progenitor cells in tumours regulate pericyte differentiation and vascular survival. Nat Cell Biol 2005;7:870-879.

47. Shono $\mathrm{T}$, Ono $\mathrm{M}$, Izumi $\mathrm{H}$, et al. Involvement of the transcription factor NF-kappaB in tubular morphogenesis of human microvascular endothelial cells by oxidative stress. Mol Cell Biol 1996;16:4231-4239.

48. Flintoff-Dye NL, Welser J, Rooney J, et al. Role for the alpha7beta1 integrin in vascular development and integrity. Dev Dyn 2005;234:11-21.

49. Welser JV, Lange N, Singer CA, et al. Loss of the alpha7 integrin promotes extracellular signal-regulated kinase activation and altered vascular remodeling. Circ Res 2007;101:672-681.

50. Garmy-Susini B, Jin $H$, Zhu $Y$, et al. Integrin alpha4beta1-VCAM-1mediated adhesion between endothelial and mural cells is required for blood vessel maturation. J Clin Invest 2005;115:1542-1551.

51. Dai J, Peng L, Fan K, et al. Osteopontin induces angiogenesis through activation of PI3K/AKT and ERK1/2 in endothelial cells. Oncogene 2009;28:3412-3422.

52. Lund SA, Giachelli CM, Scatena M. The role of osteopontin in inflammatory processes. J Cell Commun Signal 2009;3:311-322.

53. Speer MY, Chien YC, Quan M, et al. Smooth muscle cells deficient in osteopontin have enhanced susceptibility to calcification in vitro. Cardiovasc Res 2005;66:324-333.

54. Scatena M, Liaw L, Giachelli CM. Osteopontin: a multifunctional molecule regulating chronic inflammation and vascular disease. Arterioscler Thromb Vasc Biol 2007;27:2302-2309.

55. Jono S, Peinado C, Giachelli CM. Phosphorylation of osteopontin is required for inhibition of vascular smooth muscle cell calcification. J Biol Chem 2000;275:20197-20203.

56. Fruttiger M. Development of the retinal vasculature. Angiogenesis 2007:10:77-88

57. Wang $\mathrm{S}, \mathrm{Wu} Z$, Sorenson CM, et al. Thrombospondin-1-deficient mice exhibit increased vascular density during retinal vascular development and are less sensitive to hyperoxia-mediated vessel obliteration. Dev Dyn 2003;228:630-642.

58. Greenberg JI, Shields DJ, Barillas SG, et al. A role for VEGF as a negative regulator of pericyte function and vessel maturation. Nature 2008;456:809-813.

59. Bartoli M, Platt D, Lemtalsi T, et al. VEGF differentially activates STAT3 in microvascular endothelial cells. FASEB J 2003;17:1562-1564.

60. Chen Z, Han ZC. STAT3: a critical transcription activator in angiogenesis. Med Res Rev 2008;28:185-200. 